\title{
EL MAAR POLIGENÉTICO DE HULE (COSTA RICA). REVISIÓN DE SU ESTRATIGRAFÍA Y EDADES
}

\author{
THE POLIGENETIC HULE MAAR (COSTA RICA). REVISION OF ITS \\ STRATIGRAPHY AND AGES
}

\author{
Flavia M. Salani ${ }^{1 *} \&$ Guillermo E. Alvarado² \\ ${ }^{1}$ Departamento de Ciencias Geológicas, Universidad de Buenos Aires, \\ Pabellón II. Ciudad Universitaria, C-1428 EHA, Buenos Aires, Argentina \\ ${ }^{2}$ Área de Amenazas y Auscultación Sísmica y Volcánica, \\ Instituto Costarricense de Electricidad, Apdo. 10032-1000, San José, Costa Rica \\ *Autora para contacto: fms@gl.fcen.uba.ar
}

(Recibido: 01/08/2009; aceptado: 08/11/2010)

\begin{abstract}
The Hule maar belongs to an alignement of several explosive foci located in the northern side of the Costa Rica Central Volcanic Range, N and S of Poás volcano. The crater of this center is characterized by its wide extension, with a diameter over world maar average, and by its poligenetic eruptivity. The Hule maar is related to a minor explosive center as Pata de Gallo maar. A new simplified stratigraphic sequence of the main maar is proposed taking into account stratigraphy, morphology and compositional data. Pyroclastic surges, andesitic pumice flows, air fall deposits, ballistic blocks, and reworked deposits are the result of a phreatomagmatic eruptive phase, of andesitic composition. All the deposits overlie the regional basement and a basal level of organic debris. Several facies were distinguished: Sequence 1. Pyroclastic Surges and Flows (SFB-1), Stratified Tuff 1 (TE-1), Fine Violet Tuff (CV), Stratified Tuff 2 (TE-2), Sequence 2. Pyroclastic Surges and Flows (SFB-2) Stratified Tuff 3 (TE-3), Air-fall tephra (?), Lahar (Lh-Hu). A post-maar phase built up an intra-maar pyroclastic cone with associated basaltic lava flow. Analyses of avalaible radiometric data set combined with geoarcheological evidences allowed to present a new temporal schema for maar activity yielding average Hule maar eruption at 6200 years B. P. and Pata de Gallo maar at 2800 years B. P. Keywords: Maar Hule, poligenetic center, explosive volcanism, tephrastratigraphy, radiocarbon ages, Costa Rica.
\end{abstract}

RESUMEN: El maar de Hule forma parte de una serie de focos explosivos ubicados al N y S del volcán Poás, en el flanco norte de la Cordillera Volcánica Central, de costa Rica. El cráter de este centro eruptivo supera la media del diámetro de los maares a nivel mundial, y se caracteriza por una recurrencia en la eruptividad. Se destaca su asociación a centros explosivos menores como el maar de Pata de Gallo. En este trabajo se presenta una nueva secuencia 
estratigráfica simplificada de las fases explosivas de Hule sustentada en consideraciones estratigráficas, morfológicas y composicionales. Como resultado de fases eruptivas de origen freatomagmático y composiciones andesíticas, se origina una variedad de depósitos entre los que se encuentran piroclastitas de oleadas y flujo, tobas de caída, bloques balísticos y depósitos retrabajados, que sobreyacen un nivel de debris orgánico. Se han distinguido diferentes facies agrupadas como: Secuencia 1 de Flujos piroclásticos y oleadas (SFB-1), Toba estratificada 1 (TE-1), Toba fina violácea (CV), Toba estratificada 2 (TE-2), Secuencia 2 de Flujos piroclásticos y oleadas (SFB-2,) Toba estratificada 3 (TE-3), Tefras de caída (?), Lahar (Lh-Hu). Una fase post maar, más básica, construye un cono piroclástico intramaárico de tipo estromboliano, con lavas basálticas asociadas. La edad de la formación del maar de Hule se discute con base en una revisión de dataciones radiométricas previas, aspectos pedogenéticos de la secuencia explosiva y evidencias geoarqueológicas. El conjunto de datos permite proponer un nuevo esquema temporal asignando una edad de 6200 años antes del presente para la formación de la laguna Hule, y una edad de 2800 años antes del presente para la formación del maar satelital de Pata de Gallo.

Palabras clave: Maar Hule, centro poligenético, vulcanismo explosivo, tefroestratigrafía, edades radiocarbono.

\section{INTRODUCCIÓN}

La Laguna Hule se ubica $11 \mathrm{~km}$ al norte del volcán Poás, en el flanco norte de la Cordillera Volcánica Central de Costa Rica, formando parte de un extenso complejo volcánico que involucra a los volcanes Poás (conos Votos y Von Frantzius), Congo y varios centros eruptivos menores (Fig. 1). Entre los centros de menor envergadura y de origen explosivo además de Hule, se destacan la laguna Río Cuarto, $5 \mathrm{~km}$ al norte de Hule y la serie de conos piroclásticos denominados Sabana Redonda al sur del cráter principal del Poás y a $20 \mathrm{~km}$ de Hule.

El rasgo distintivo del conjunto volcánico es la alineación de los centros según fisuras de orientación N-S que responden a la tectónica regional. Siguiendo este lineamiento se disponen efusiones andesítico basálticas de aproximadamente 200000 años que constituyen un campo de lavas de suave relieve, aún con los frentes de lavas reconocibles, como se observa tanto en cercanías de Hule como próximo a Río Cuarto (Carr et al., 2007).

El área ha sido estudiada por su interés geológico y geotécnico, y particularmente por el potencial peligro de las erupciones y su influencia en obras civiles en construcción como las desarrolladas por los Proyectos Hidroeléctricos Cariblanco y Toro 3, llevadas a cabo por el ICE (Instituto Costarricence de Electricidad). Precisamente, por este motivo se realizó un estudio completo y extenso sobre el Peligro Volcánico que contempló

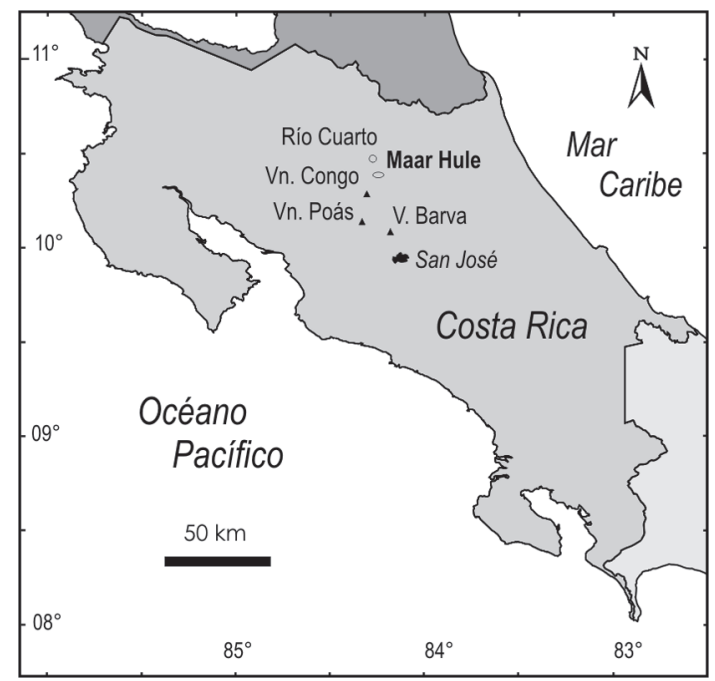

Fig. 1: Mapa de ubicación.

los levantamientos estratigráficos de detalle presentados previamente por los autores (Alvarado \& Salani, 2004). La continuidad de las labores en el marco de ambos proyectos, permitió realizar observaciones en nuevos y profundos cortes artificiales, que dejaron entrever una estratigrafía mucho más completa. Estas nuevas exposiciones muestran los productos explosivos cercanos al centro eruptivo Hule, y plantearon una serie de incógnitas que motivaron una revisión de los análisis previos.

En el presente trabajo se dan a conocer los nuevos datos tefro-estratigráficos obtenidos $\mathrm{y}$ una actualización de los productos explosivos de Hule. La edad del maar de Hule es discutida a la luz de nueva información radiométrica, estratigráfica y arqueológica. De este conjunto de 
datos surge una nueva interpretación de la historia eruptiva y la reubicación temporal del evento volcánico explosivo.

\section{LA DEPRESIÓN DE HULE}

La depresión de Hule (Fig. 2) ubicada entre el escarpe de falla de San Miguel y el volcán Congo, incluye las lagunas, Hule, Congo y Bosque Alegre. Estas dos últimas en períodos de lluvias extremas se encuentran comunicadas mientras que Hule y Congo están permanentemente desconectadas y separadas por una colada basáltica que forma una barrera de escaso relieve entre ambas (Soto, 1999).

Particularmente, la laguna Hule ocupa una depresión de origen freatomagmático (con sus bordes sur y norte a 960 y 760 m s.n.m., respectivamente) que abarca un área de $4 \mathrm{~km}^{2}$, y presenta una forma subcircular definida por un eje mayor de 2,3 km y uno menor de $1,8 \mathrm{~km}$. Las paredes tienen entre 110 y $230 \mathrm{~m}$ de altura con pendientes variables $\left(27-35^{\circ}\right)$. La profundidad del agua alcanza los 26,5 m. La formación de este cráter de explosión ha producido una variedad de depósitos entre los que se encuentran piroclastitas de oleadas y flujo, tobas de caída, bloques balísticos y depósitos retrabajados.

En el interior de la depresión volcánica se destaca un cono piroclástico de $500 \mathrm{~m}$ de diámetro al igual que la efusión contemporánea de lavas que se interponen entre las lagunas Hule y Congo. La lava y los depósitos del cono intramaárico son basaltos hasta andesitas basálticas con olivino (Tournon, 1984; Malavassi,1991). Próximo a la laguna Hule se encuentra el cráter de explosión Pata de Gallo (también conocido como Ángeles), una depresión de 25 a $50 \mathrm{~m}$ de profundidad y $400 \mathrm{~m}$ de diámetro, cráter que se instaló posteriormente a la formación del maar de Hule.

Resulta interesante que el cráter maárico de Hule se sale de la media en el diámetro de los maares a nivel mundial, ocupando su diámetro 2,3 $\mathrm{km}$ un extremo, mientras que, el maar de Pata de Gallo, con 400 m de diámetro, ocupa el otro extremo de la media. Éste último es un cráter satélite o

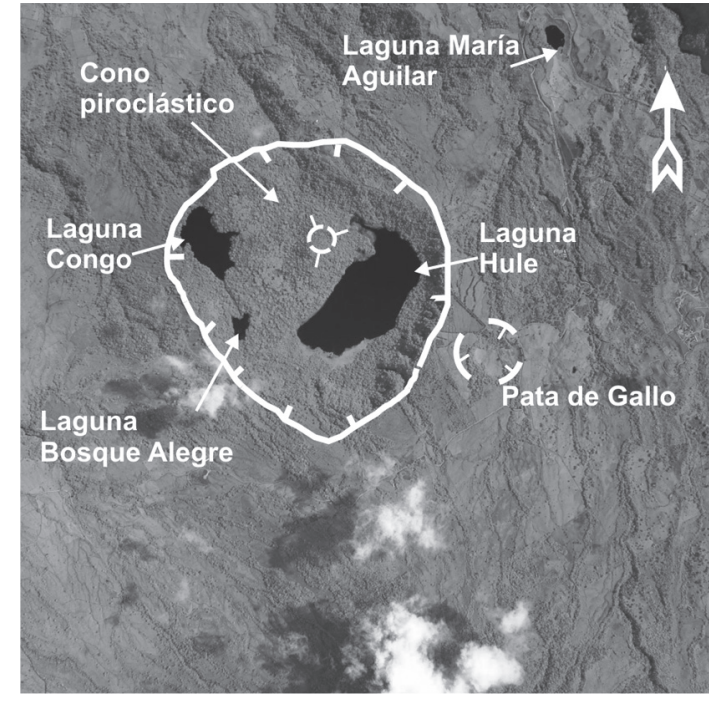

Fig. 2: Depresión de Hule.

secundario del volcán Hule, dado que corta toda la secuencia explosiva de Hule (Figuras 2 y 3 ).

\section{ANTECEDENTES}

El primer reconocimiento tefroestratigráfico y cronológico de la región obedece a Melson et al. (1988) quién dató en $5140 \pm 150$ años a.P. un flujo piroclástico que atribuyeron al Congo por su cercanía relativa. Posteriormente, Malavassi et al. (1990) obtienen una edad ${ }^{14} \mathrm{C}$ de $2730 \pm 50$ a.P. que consideran representa la edad de formación de la laguna Hule, por su cercanía relativa, aunque obvian que igualmente se encontraba en el borde del cráter maárico de Pata de Gallo. Dicha edad una vez calibrada, se le asignó a unos 2800 años a.P. Ambos trabajos adolecen de estudios tefroestratigráficos (mapas de isopacas e isopletas, columnas estratigráficas y su correlación) y de estudios geoarqueológicos.

En cuanto a la génesis de la estructura volcánica, ésta fue atribuida a un colapso de caldera (Bergoeing \& Brenes, 1978; Madrigal \& Rojas, 1980; Tournon, 1984) y posteriormente interpretada como un maar (Soto \& Alvarado, 1989).

Los estudios geoquímicos de los productos de Hule son escasos y en general corresponden a muestras aisladas tal y como lo presentan los trabajos de 


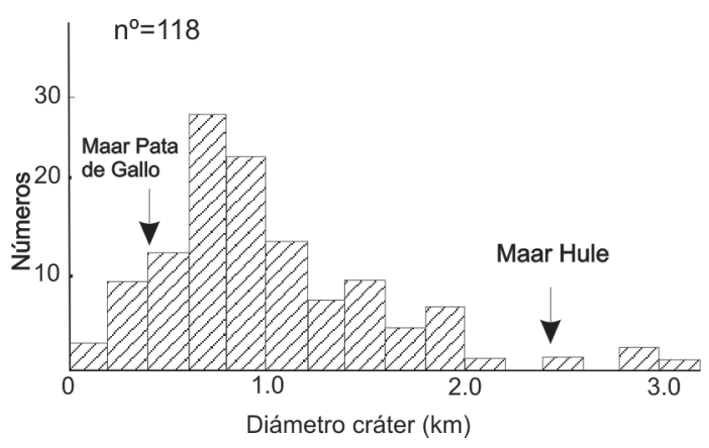

Fig. 3: Representación de diámetros más frecuentes de maares (Wood en Cas y Wright, 1987).

McBirney \& Williams (1965), Tournon (1984), Prosser \& Carr (1987), Malavassi (1991) y Soto (1999).

Un levantamiento geológico regional del área del volcán Poás, con una propuesta estratigráfica, se puede encontrar en los trabajos de Soto (1999) quien asigna las tefras de Hule como pertenecientes a la Unidad Bosque Alegre. Horn (2001) aporta un número cuantioso de fechas radiocarbónicas, tanto de muestras de sedimentos y como de sus contenidos orgánicos de las lagunas Hule y María Aguilar. Otros estudios detallados referentes a la estratigrafía del maar de Hule en donde se incluye dataciones radiocarbónicas se deben a Alvarado \& Salani, (2004) y el aporte de información arqueológica según Hurtado de Mendoza (2006). Todo ello ha contribuido a la resolución de la edad del conjunto explosivo-efusivo, y a establecer que las facies previamente asociadas con el volcán Congo, ahora corresponden más bien a la formación del maar de Hule.

Aspectos como la morfología, geoquímica de aguas de la laguna y limnología fueron presentados por Umaña (1993), Gocke et al. (1987), Gocke et al. (1987, 1990), Haberyan \& Horn (1999) y Tassi et al. (2009).

\section{TEFROESTRATIGRAFÍA}

Se realizaron observaciones y levantamiento de perfiles en estaciones (unas 60) organizadas en "transectas" dispuestas a lo largo de los cursos de los ríos Toro y Sarapiquí complementando los perfiles de trabajos anteriores (Figura 4). Las observaciones en nuevos tajos, resultado del avance de las obras del P.H. Cariblanco, tuvieron como objetivo considerar las variaciones laterales y en profundidad de las unidades. Se exponen dos columnas representativas relevadas en el área del Tanque de Oscilación Los Higuerones (T.O.) y la columna del Frente de Túnel (F.T.) así como las correlaciones establecidas a lo largo de dos lineaciones principales, una desde la región del Embalse hasta la sección del río Toro y otra que involucra estaciones desde Pata de Gallo hasta Río Cuarto (Figs. 5y 6).

Se lograron distinguir y agrupar siete diferentes facies explosivas relacionadas con la laguna Hule (excluyendo el basamento relativo local).

\section{Paleosuelo (basamento pre-Hule)}

La base de la secuencia explosiva de la laguna Hule está representada por un suelo desarrollado sobre una toba naranja (anaranjado amarillento) muy arcillosa, con clastos juveniles (vesiculados y no vesiculados) y líticos pre-existentes, que suele sobreyacer a un lahar consolidado. El suelo en el contacto con las tefras puede ser café, pero en profundidad suele pasar a un fuerte color naranja. Los suelos son el resultado de depósitos volcánicos muy alterados, que constituyen el basamento local y relativo para las tefras de Hule, que vendrían a representar el único evento volcánico claramente reconocido en la región cordillerana y ampliamente distribuido durante el período Holoceno (últimos 11500 años).

\section{UNIDADES RELACIONADAS AL MAAR DE HULE}

\section{Debris orgánico basal (DOB)}

Consiste en un depósito de detritos de vegetación (troncos, corteza, ramas), incluyendo troncos de hasta $20 \mathrm{~m}$ de longitud por 1,5 $\mathrm{m}$ de 


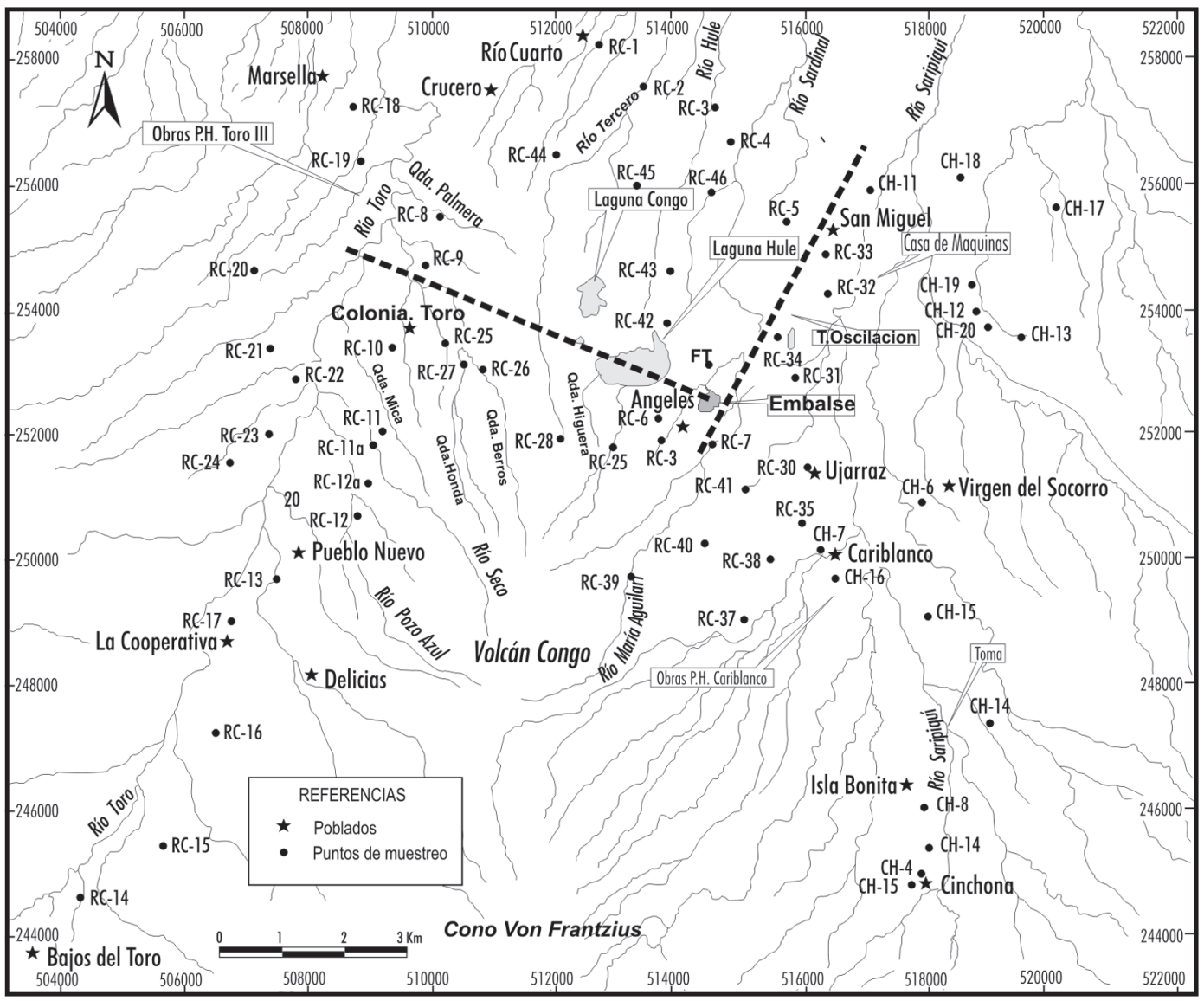

Fig. 4: Ubicación de áreas de relevamiento. Se señalan los perfiles de correlación estratigráficos. Embalse-Colonia Toro y Los Ángeles- Río Cuarto.

diámetro, parcialmente carbonizados, con espesores variables entre 0 hasta $2 \mathrm{~m}$ de potencia. Constituye en varios lugares la base de la secuencia explosiva (Fig. 7).

La abundancia de vegetación estaría indicando la presencia de un paleobosque. Los detritos se interpretan como producto de una destrucción rasante por la explosión y onda de choque durante la apertura explosiva del maar.

La capa de material vegetal incinerado, resultante del evento Hule, expuesta a raíz de las obras constructivas en el Tanque de Oscilación (sitio arqueológico Los Higuerones), proveyó una fecha de radiocarbono cuya versión conven- cional la ubica en el año $5390 \pm 45$ a.P. (Hurtado de Mendoza, 2006), que una vez calibrada y promediada resulta en 6230 años a.P.

\section{Secuencia 1. Flujos piroclásticos y oleadas (SFB-1)}

Sobre el DOB o sobre el paleosuelo regional, se dispone una compleja secuencia de escombros volcánicos con niveles de lapillitas pumíceas y tobas subordinadas con un espesor total máximo de 11,5 m (p.ej., T.O. Los Higuerones, Figura 6). En la base se encuentra una toba café y violácea, 


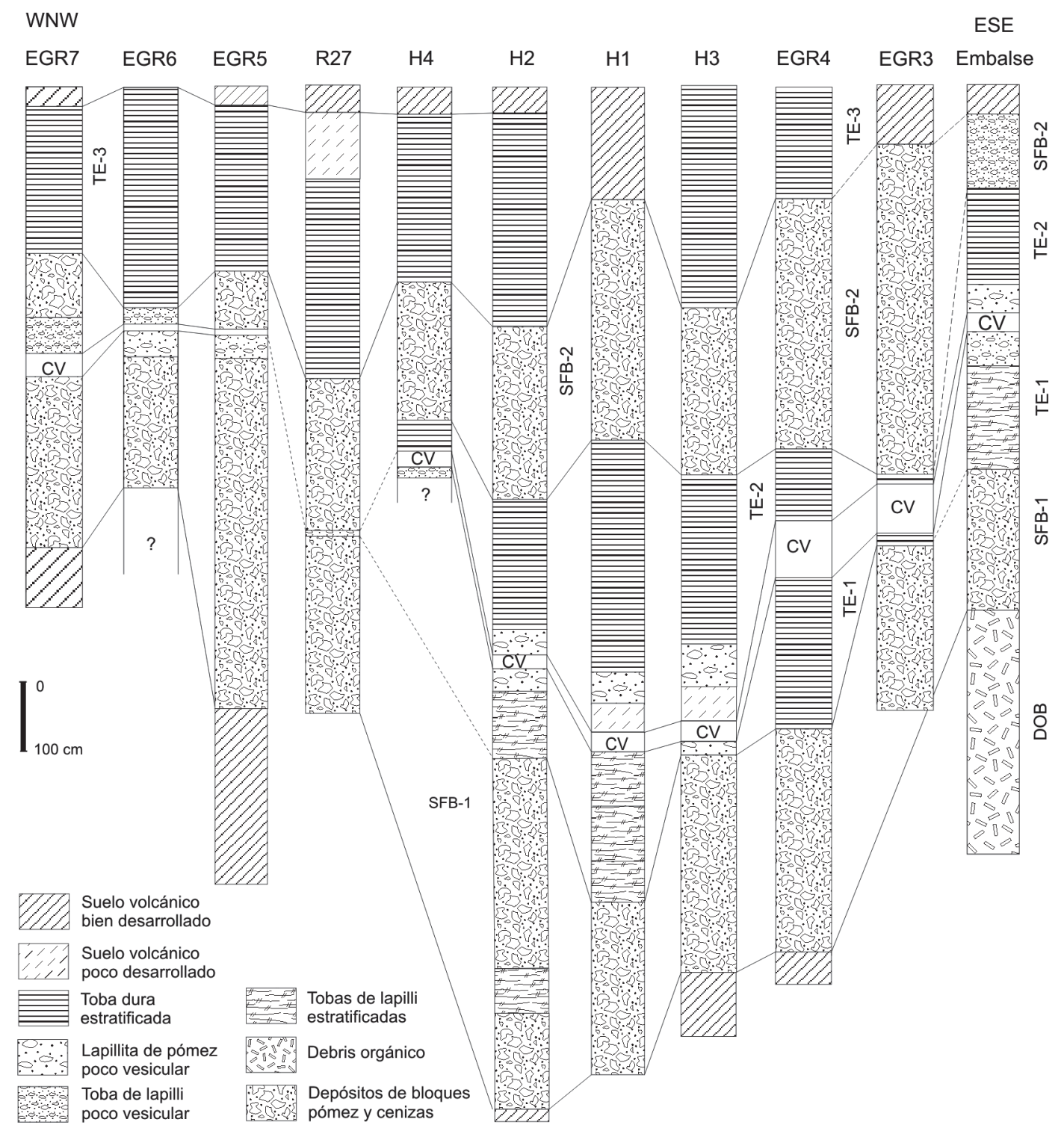

Fig. 5: Correlación de columnas estratigráficas Embalse-Colonia Toro.

seguida por nueve niveles de lapilli andesíticos de $0,4 \mathrm{~m}$ de espesor promedio y brechas polimícticas de pómez y bloques, con espesores entre 0,5 y 2 $\mathrm{m}$ como máximo. Los niveles de lapilli muestran componentes de 2-6 cm de diámetro, suelen poseer contacto puntual, fábrica abierta y algo de cenizas.

Referente a los niveles de escombros volcánicos, un primer nivel está representado por una capa rica en detritos volcánicos alterados representado por brechas de pómez, lapilli pumíceos, barros de cenizas blandas y lapilli alterados.

Los depósitos de bloques y cenizas están compuestos por bloques juveniles andesíticos vesiculados (pumíceos) hasta poco vesiculados con anfíbol, de color gris oscuro a claro, de hasta unos $15 \mathrm{~cm}$ cómo máximo. Un $10-30 \%$ de los bloques pertenece a no juveniles andesíticos afíricos o bien porfiríticos, vesiculares e hidrotermalizados, 

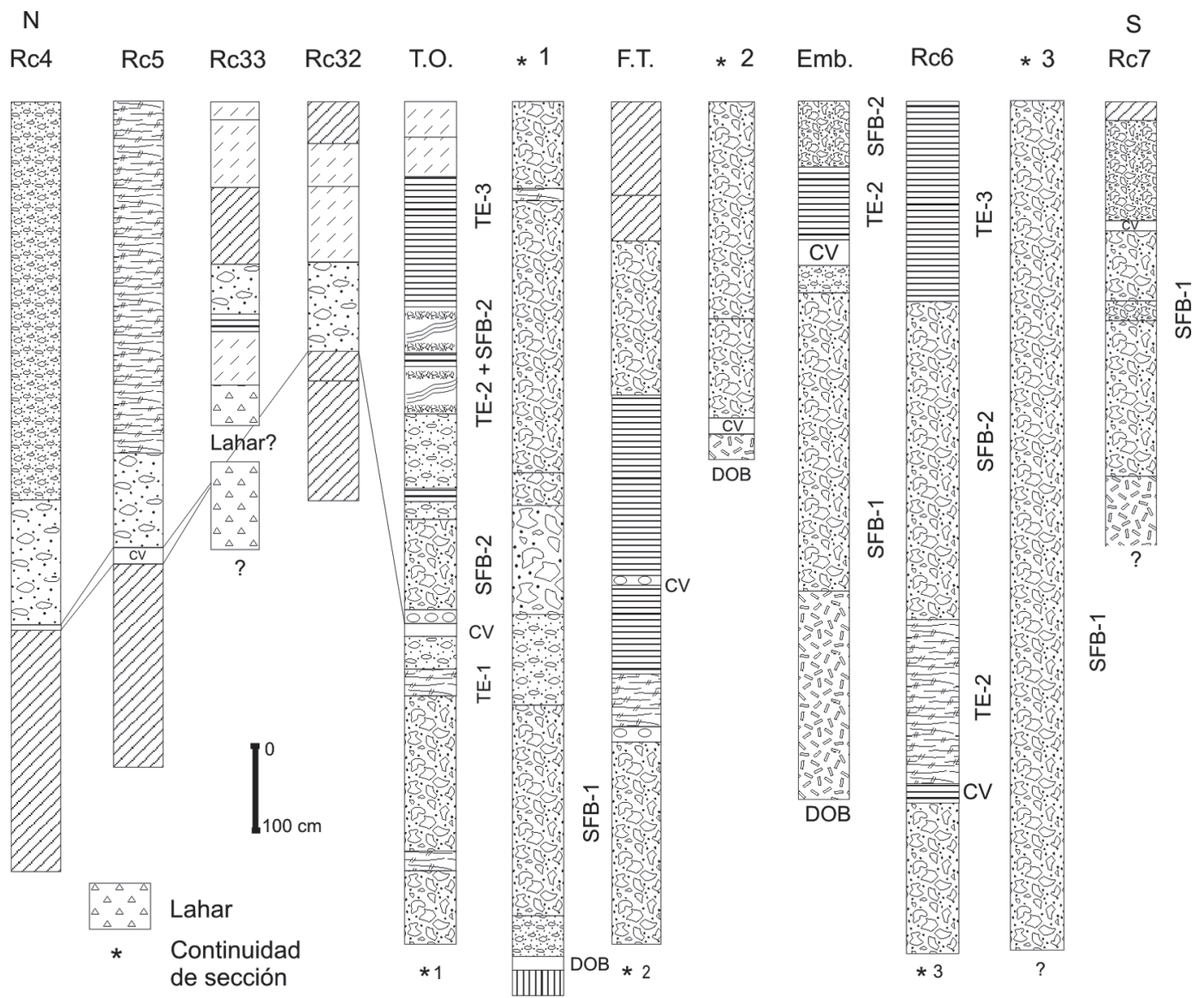

Fig. 6: Correlación de columnas estratigráficas Los Ángeles- Río Cuarto. Mismas referencias que en la figura 5.

de hasta unos $50 \mathrm{~cm}$ de diámetro, pero generalmente de unos $10 \mathrm{~cm}$ de diámetro promedio, embebidos en cenizas gris claro (30-65\%) con un contenido de potasio mediano a bajo (Soto, 1999). Forman un manto de hasta varios metros de espesor, normalmente entre 1,25 y 3,5 m. El depósito puede estar groseramente estratificado compuesto por 1 a 5 capas de tobas finas y tobas de lapilli hasta brechas andesíticas, localmente con gradación inversa, contactos transicionales a poco definidos, $\mathrm{y}$ espesores variables entre $23 \mathrm{~cm}$ y $1,5 \mathrm{~m}$.

Los flujos de pómez han sido identificados hasta $7 \mathrm{~km}$ del cráter. En áreas como la Quebrada Palmera $(255,55 \mathrm{~N}-510,15 \mathrm{E})$ el depósito está representado por un flujo pardo con fragmentos juveniles de color blanco, subredondeados y fragmentos grises juveniles con un $Ф$ Max de $4 \mathrm{~cm}$, flotantes en una matriz café clara. En la quebrada Culebra también se observaron depósitos pumíceos posiblemente de flujo. En la quebrada Berros, está expuesto un flujo piroclástico cuya sección inferior muestra escasa proporción de juveniles, granulometría fina y lapilli acrecional de 1 a $3 \mathrm{~cm}$ de diámetro. Separando este sector de la sección superior aparece una capa de ceniza mediana a gruesa de $4 \mathrm{~cm}$ de espesor que presenta niveles lenticulares, estructuras de truncamiento y adelgazamientos laterales. La sección superior, de color gris claro a violácea, está alterada, en un primer tramo de $1 \mathrm{~m}$ para continuar con $1,5 \mathrm{~m}$ de un depósito color pardo con componentes juveniles de ФMax $3 \mathrm{~cm}$ y no juveniles de $3-4 \mathrm{~cm}$ en cuya base se destacan líticos de $8 \mathrm{~cm}$. En el sector medio del depósito, los juveniles tienen un $\Phi$ entre 2 y $3 \mathrm{~cm}$. 


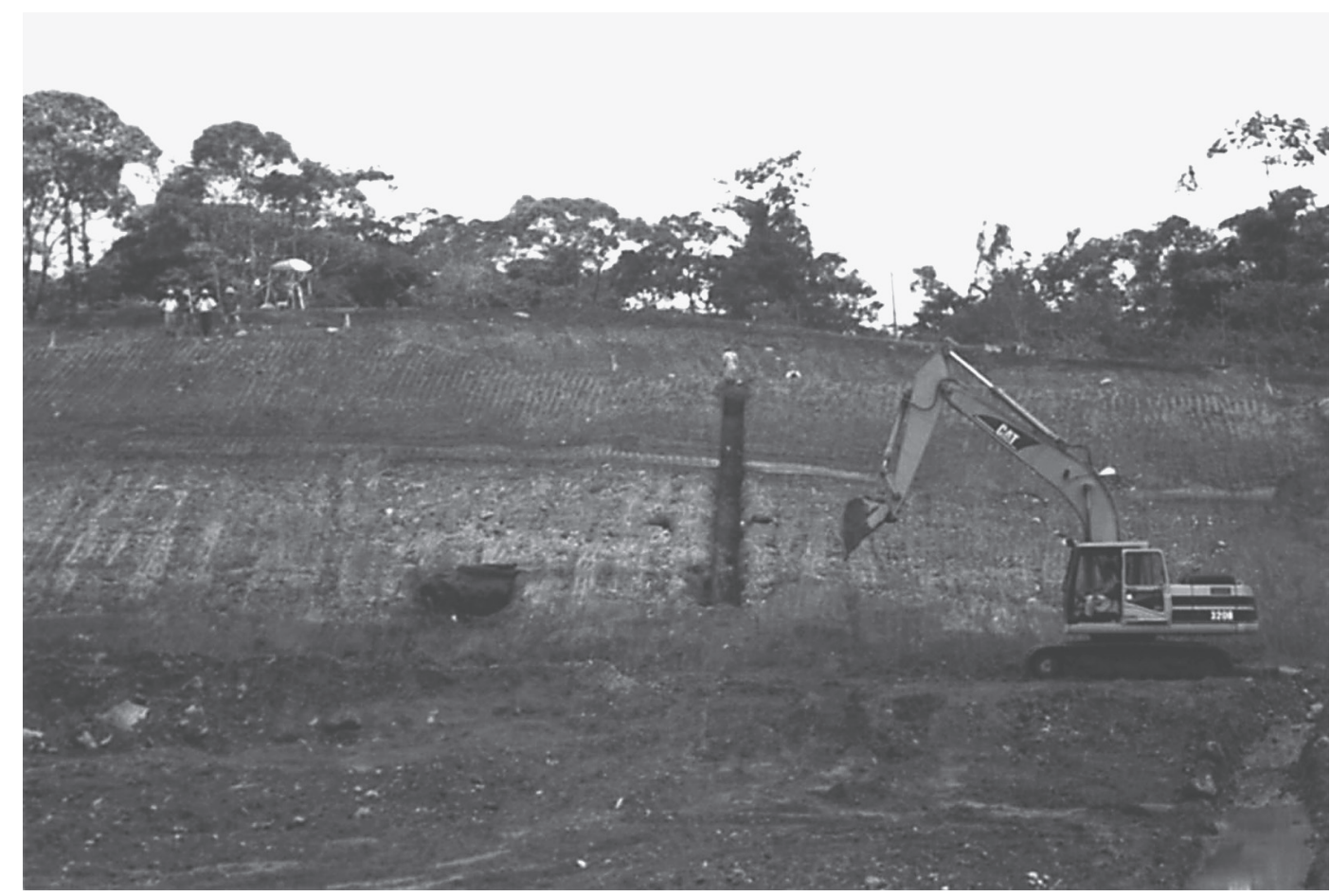

Fig. 7: Corte en el embalse del Proyecto Cariblanco (514 830 - 252 651), en donde se observa en la parte inferior un nivel oscuro en correspondencia con un debris orgánico basal (troncos métricos, ramas y detritos orgánicos carbonizados), en correspondencia con un paleobosque (capa DOB). La delgada capa intermedia de tono claro, corresponde con la capa guía violácea (CV).

Los atributos texturales de los niveles de lapilli andesíticos sumado a la presencia de cenizas, podrían indicar un origen de capas de caída subpliniana. Sin embargo, la poco clara y escasa distribución en el área, sus variaciones laterales en el espesor a escala de afloramiento, el hecho de poseer debris orgánico totalmente carbonizado y bosques arrasados a su base, estarían indicando una génesis de los depósitos de oleadas piroclásticas pumíticas secas y calientes (tipo blast) asociadas con los flujos piroclásticos, similares a las del Arenal en 1968 (Alvarado et al., 2006).

Los niveles de escombros volcánicos basales son de difícil interpretación dado que por un lado simulan debris flows y por otro parecen flujos piroclásticos. Si se tiene en cuenta que se les encuentra en partes altas, y están representados por un primer nivel rico en detritos volcánicos alterados (brechas de pómez, pómez, barros blandos, lapilli alterado), más bien parecen ser las brechas de explosión de apertura de la caldera maárica.

Los niveles de bloques y cenizas claramente corresponden con flujos piroclásticos, algunos de ellos con menor cantidad de líticos (verdaderos flujos de pómez) mientras que otros parecen ser flujos de bloques y cenizas. Su estructura masiva, pobre selección, abundancia de fragmentos juveniles, existencia de materia orgánica carbonizada, y mayor espesor en los valles, soportan lo anterior. La presencia de lapilli acrecional es un indicio de participación de vapor de agua, ya sea de origen freatomagmático o producto de la condensación del agua atmosférica con las cenizas.

\section{Toba estratificada 1 (TE-1)}

Depósito de cenizas estratificado con laminaciones paralelas, constituida por intercalaciones de tobas finas y tobas de lapilli con clastos 
centimétricos. Localmente puede presentarse hacia la base una capa de ceniza negra a fina con clastos líticos de hasta $10 \mathrm{~cm}$ de diámetro $\mathrm{y}$ un fuerte adelgazamiento lateral. Su espesor máximo medido es de unos $1,4 \mathrm{~m}$ y tan solo se le ha observado en una sección estratigráfica (EGR4 o 2C, Fig. 5 y 8).

Claramente se trata de una condición local que se interpreta como una dilución lateral de los flujos de bloques y cenizas contemporáneos con las oleadas pumíticas secas (blasts).

\section{Toba fina violácea $(\mathrm{CV})$}

Inmediatamente sobre el primer depósito de flujos SFB-1, suele aparecer una capa de toba de color violeta-morada o rosado-rojiza, de grano muy fino y plástica a grano grueso y menos plástica, y una toba de lapilli color café claro, que localmente puede contener lapilli acrecional (p. ej. EGR4, Fig. 5). Su espesor varía entre 0 y $50 \mathrm{~cm}$, y aún a escala de afloramiento puede variar lateralmente; constituye, sin embargo, una capa guía de correlación estratigráfica. Suelen presentar estratificación y laminación paralela, ambas difusas, y cierta gradación en rombo; su selección varía de buena a regular. El depósito está integrado por componentes juveniles con $\Phi 1 / 2$ homogéneos en las secciones medidas y en el orden de los 1-2 cm, excepcionalmente 3 y $5 \mathrm{~cm}$. Puede contener en su base una toba fina café, transicional a un posible suelo pobremente desarrollado o bien simplemente ser una ceniza algo alterada o freática (columnas H-2 y H-3). Infrayace a las tobas estratificadas superiores (TE-3), es decir las más distribuidas de Hule, o en otros lugares se encuentra cubierta por los flujos piroclásticos (SFB2), mostrando estructuras de impacto que deforman y hasta hacen desaparecer la capa (Fig. 9).

Dada su variación en el espesor, aún a escala de afloramiento, el alto grado de fragmentación, cohesividad y la presencia de lapilli acrecional, el origen más probable es por oleada piroclástica (base surge). Su pobre granoselección local se puede atribuir a la incorporación de fragmentos líticos en el avance del flujo o que haya habido una caída de líticos simultánea.

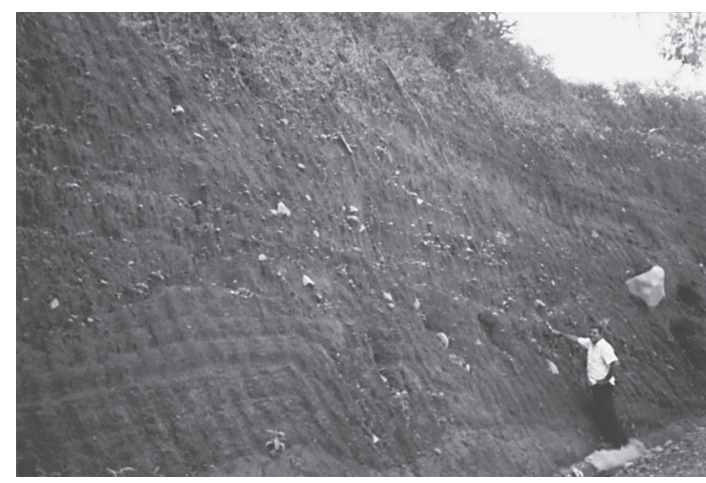

Fig. 8: Sección estratigráfica en el camino entre Los Ángeles y Colonia Toro que muestra una alternancia de depósitos lapíllicos con estratificación planar y lenticular bien definida, tanto en su parte superior como inferior, con un nivel intercalado de brechas (cenizas y lapilli con bloques de impacto) asociados con Hule. Sobreyacen a un paleosuelo regional, que se observa en la parte inferior de la fotografía.

\section{Toba estratificada 2 (TE-2)}

Está restringida a un abanico de escasos $3 \mathrm{~km}$ de ancho máximo hasta $1,5 \mathrm{~km}$ al $\mathrm{SW}$ de la laguna Hule. Corresponde con una secuencia de tobas (ceniza media a gruesa) estratificadas color marrón oscuro a café claro, con clastos centimétricos subangulares, localmente con estratificación paralela curva y lentes de lapilli de material juvenil. Puede presentar estratos intercalados de tobas consolidadas (laminadas y con lapilli acrecional) y menos consolidadas, con espesores de 2-5 cm y 10-20 cm, respectivamente. Presenta estructuras de canal e impacto, así como antidunas con longitud de onda entre 4,8 y $6,3 \mathrm{~m}$. Su espesor varía entre $0,6 \mathrm{~m}$ y $2 \mathrm{~m}$. Lateral y verticalmente parece gradar a la unidad SFB-2.

La presencia de estratificación paralela y curva, así como de antidunas de moderada longitud de onda, pueden atribuirse a oleadas piroclásticas rasantes (base surges). Los cráteres de impacto y la presencia de gran cantidad de lapilli en algunos niveles, y el hecho de aparentemente gradar lateral y verticalmente hacia la segunda secuencia de flujos piroclásticos (SFB-2) inducen a pensar en la concomitancia de caída balística y de flujos piroclásticos que localmente se diluían a oleadas. 


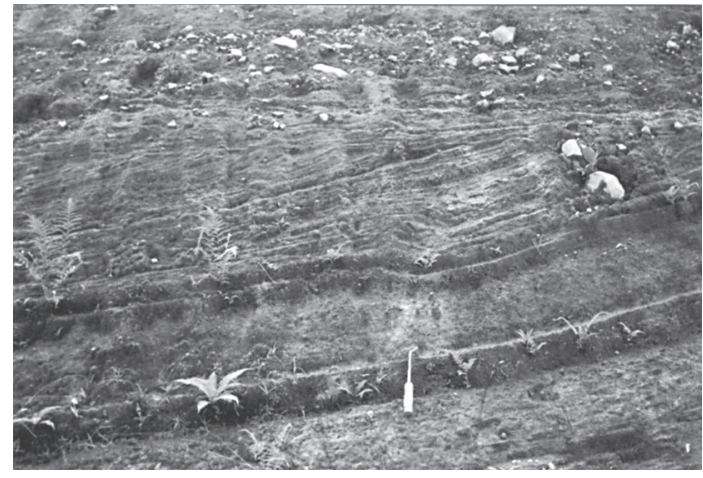

Fig. 9: Sección estratigráfica que muestra una alternancia de depósitos lapillíticos con estratificación planar y lenticular bien definida en su parte superior (TE-2), con un nivel intercalado masivo de cenizas violáceas $(\mathrm{CV})$, algo deformada, todo sobreyacido por medio de una discordancia local producto de la erosión de los flujos piroclásticos superiores (SFB-2). Ubicada en el camino entre Los Ángeles y Colonia Toro.

\section{Secuencia 2 de Flujos piroclásticos y oleadas (SFB-2)}

Consiste de depósitos de bloques y cenizas con clastos juveniles andesíticos con anfíbol (vesiculados a poco vesiculados), de 1-3 cm de diámetro aunque muestran dimensiones máximas de $12 \mathrm{~cm}$. Los fragmentos líticos son andesíticos de $20 \mathrm{~cm}$ de diámetro, e inclusive métricos, subangulares a subredondeados, flotantes y en contacto puntual en una matriz (60-75\%) de lapilli fino y cenizas, color café rojizo a gris, mal seleccionada. Pueden presentarse algunos paquetes centimétricos intercalados o interestratificados, particularmente en su base y techo, de tobas finas, tobas vesiculares y tobas de lapilli andesítico o inclusive entre 1 a 5 capas algo definidas con espesores variables entre $10 \mathrm{~cm}$ y $1,4 \mathrm{~m}$, por lo general entre 0,2 y $0,5 \mathrm{~m}$ de espesor. Su espesor total varía entre $60 \mathrm{~cm}$ y $3 \mathrm{~m}$. Localmente, se encuentran bloques balísticos en su base con dimensiones entre 35 y $85 \mathrm{~cm}$.

También se presenta una capa de lapilli de grano medio con fragmentos de pómez con anfíbol, que presenta contacto puntual y espesores entre 6 y $56 \mathrm{~cm}$. Está cubierta localmente por un depósito de bloques y cenizas de hasta 60-300 cm de espesor, con líticos generalmente centimétri- cos a decimétricos (en promedio tienen $8-15 \mathrm{~cm}$ ), algunos métricos, claramente mal seleccionados, en una matriz que constituye entre $40-80 \%$ de ceniza fina café.

Las facies gruesas presentaban buenas exposiciones en los cortes del camino que une Río Cuarto-San Miguel (Alvarado \& Salani, 2004), hoy día cubiertos de vegetación. Está integrada por depósitos masivos sin estratificación o pobremente estratificados, de color gris blanquecino, granosoportados, con un espesor que varía de 1,7 a $5 \mathrm{~m}$, caracterizados por el predominio de lapilli juveniles sanos y líticos con distinto grado de alteración, oxidados e hidrotermalizados. Los componentes juveniles sanos son densos de color gris verdoso oscuro con un $\Phi$ Max $=4 \mathrm{~cm}$ y $\Phi 1 / 2=1-2$ $\mathrm{cm}$; los fragmentos líticos no juveniles se presentan de color blanco verdoso cuando están completamente alterados, y rojizos cuando están oxidados e hidrotermalizados. Poseen un ФMax de 7-10 $\mathrm{cm}$. En la base de los depósitos aparecen capas de lapilli más gruesos con $\Phi 1 / 2=1-4 \mathrm{~cm}$ en los que se destacan bloques balísticos no juveniles de $8 \mathrm{~cm}$ de longitud y juveniles del mismo tamaño.

Esta fase reúne depósitos con variedad de características, granulométricas, composicionales, estructurales y texturales así como de espesor de los paquetes interestratificados, aún a escala de afloramiento o en distancias de 250 $\mathrm{m}$. Claramente, diferentes procesos piroclásticos debieron de interactuar para originar esta amplia gama de depósitos, que incluye desde flujos de bloques, pómez y cenizas y quizás caída (eólica y balística). También habrían intervenido procesos sedimentarios posteriores resultando en el retrabajo parcial de algunos niveles.

\section{Toba estratificada 3 (TE-3)}

Corresponde con una secuencia de tobas duras (cenizas finas a gruesas fuertemente compactadas), algunas tobas vesiculadas y capas de lapilli angular a subredondeado, andesítico basáltico, grueso a medio; alternadas con tobas lapillíticas estratificadas duras. Su color varía entre café amarillento, café oscuro a claro, gris café 
(beige), o café rojizo claro hasta anaranjado, con estratificación centimétrica, estructura planar horizontal, discontinua y continua, con lapilli de $\Phi 1 / 2=1-4 \mathrm{~cm}, 2 \mathrm{~cm}$ como promedio. Los estratos pueden tener laminación paralela y ondulada, y localmente son ricos en lapilli acrecional $(0,5$ $\mathrm{cm}$ de diámetro). Presentan improntas de materia orgánica sustituidas por óxidos de manganeso. En proximidades de la laguna Hule, los depósitos muestran mayor granulometría y se reconocen clastos de proyección balística (bomb sag structure) de hasta $80 \times 50 \times 40 \mathrm{~cm}$, deformando las cenizas por el impacto, y otras estructuras de deformación sineruptiva o ligeramente post-eruptiva, tales como slumps y hasta discordancias internas.

En efecto, una serie de estructuras discordantes internas se han observado dentro de estas tobas estratificadas, reconocibles a 1,2-2,5 km de la entrada a Colonia Toro con rumbo a Hule (p.ej., quebradas Honda, Berros). Las tobas estratificadas presentan en su parte media superior, una estructura de canal, estructuras tipo slump hasta bloques coherentes de tobas estratificadas volcadas o basculadas. Algunas de estas estructuras de forma acanalada, suelen tener lentes de guijarros andesítico-basáltico y escorias con un tamaño promedio de $2 \mathrm{~cm}$, forma subangular a subredondeada y estratificación grosera (Fig. 10). Están discordantemente dispuestas con respecto a las tobas que están en la vecindad inmediata y conforman las paredes del canal.

Las tobas TE-3 cubren un área amplia que se extiende desde la laguna Hule unos $7 \mathrm{~km}$ al oeste del centro emisor y unos $3 \mathrm{~km}$ al suroeste. Presentan una asimetría en los espesores con un máximo localizado en las inmediaciones de la laguna y el segundo en el área occidental en el sector de Quebrada Honda y a $1 \mathrm{~km}$ de la casa de Máquinas. Los espesores medidos están en un rango en general de 1 a $2,5 \mathrm{~m}$ y un mínimo de $35 \mathrm{~cm}$ en las secciones más alejadas sobre el río Toro. En el sector cercano a la casa de Maquinas de Toro 2 la toba se encuentra rellenando canales.

Las características del depósito tales como estratificación y laminación paralela discontinua, laminación inclinada y cruzada, estructuras de erosión y relleno, ripples y antidunas, permiten

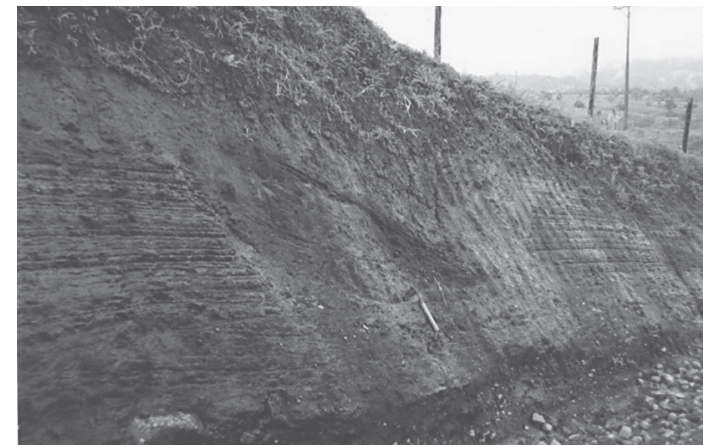

Fig. 10: Canales de erosión prácticamente, en donde se observa las capas de tobas de oleadas (nivel TE-3), cortadas y rellenas por bloques de tobas basculados y slumps, así como guijarros y arenas volcánicas, cubiertos finalmente por los suelos más recientes. Observaciones en el camino entre Los Ángeles y Colonia Toro.

atribuirle un origen por oleadas piroclásticas. Los dos máximos en los espesores encontrados podían ser en el primer caso y más cercano, el resultado de oleadas (flujos turbulentos) que se desplazan por los laterales del maar en contacto con el terreno (base surge) y en el otro caso (segundo máximo) el resultado de una componente de caída asociada a la oleada (ash cloud surge).

\section{Tefras de caida (?)}

Los depósitos de tefra de caída posiblemente relacionados con el cráter de explosión de Hule fueron reconocidos y descritos por Alvarado \& Salani (2004) en la falda norte del volcán, al noroeste de la laguna Hule y en el tramo inferior del río Toro. En general están separados de las unidades más antiguas por suelos. El espesor de los depósitos oscila en un rango entre $80 \mathrm{~cm}$ y $20-15$ $\mathrm{cm}$ en el sector más occidental del volcán Congo, en la margen izquierda del río Toro. El color general es pardo claro, están representados por capas de lapilli y tobas de lapilli, con buena selección y con carácter granosoportado. En los sectores distales como Río Cuarto están compuestos por juveniles grises, pómez blancas con $\Phi \max =1-2 \mathrm{~cm}$. En la base aparecen fragmentos aislados morados y blancos de hasta $5 \mathrm{~cm}$ y juveniles andesíticos de $5 \mathrm{~cm}$. En Quebrada Honda son lapillitas con fragmentos juveniles andesíticos de $3 \mathrm{~cm}$ con anfíboles 
y no juveniles de hasta $6 \mathrm{~cm}$. En las facies más proximales, en Quebrada Mica, presentan pómez de $\Phi \max =4-5 \mathrm{~cm}$ con aislados líticos balísticos poco vesiculados de $7-20 \mathrm{~cm}$.

Estos depósitos fueron originalmente mapeados como caída por su buena selección, y por la presencia de poca matriz. Sin embargo, resultan de difícil interpretación a la luz de los nuevos cortes, sin poder establecer si son efectivamente caída eólica normal o si existe en algunos de ellos una componente lateral tipo blast.

\section{Lahar (Lh-Hu)}

En la sección estratigráfica RC 2 en el área de Río Tercero (Fig. 4), se observó un depósito caótico de un espesor de 1,5 m, de arenas y limos volcánicos (cenizas retrabrajadas), y arcillas de color gris oscuro, con cantos rodados, enriquecido en grandes troncos. La madera está quemada totalmente o con bordes de deshidratación. Se distinguen fragmentos de andesitas, redondeados, con $\Phi$ Max $=1,5 \mathrm{~cm}$, y fragmentos juveniles vesiculados de $\Phi=15 \mathrm{~cm}$ de color gris oscuro.

Una datación radiocarbónica indica la contemporaneidad entre este depósito epiclástico (edad calibrada promedio 5925 años; Alvarado \& Salani, 2004), en correspondencia con la edad de los eventos explosivos, particularmente los flujos piroclásticos y blasts, previamente descritos. La presencia de cenizas y pómez junto con los cantos rodados, así como su estructura masiva y mal seleccionada, indicaría que se trata de un debris flow (lahar) aunque los troncos quemados señalarían un efecto de temperatura y, por ende, podría tratarse de un flujo piroclástico transformado en un lahar caliente, por incorporación de agua en el cauce del paleo-río Tercero. Otra posibilidad, es que se trate simplemente de un lahar frío que transportó parte del bosque quemado y arrasado por los flujos piroclásticos.

\section{Fase Post-maar}

Luego de la construcción del maar de Hule se produjo una erupción de tipo estromboliano que condujo a la formación de un cono piroclástico intramaárico con coladas de lava subordinadas.

El cono denominado Bosque Alegre, posee $500 \mathrm{~m}$ de diámetro aproximadamente, muestra un relieve tendido y es resultado de aglutinación de material escoreáceo (Fig. 11). La roca característica es porfirítica, está constituida por $25-34.5 \%$ de fenocristales de plagioclasa (17-25\%), ol (2-4\%), cpx (2-4\%), mt (1-2\%) en una matriz intergranular a intersertal de microlitos de plagioclasa, opacos, cantidades variables de clinopiroxeno, vidrio pardo, olivino y trazas de hematita.

Asociadas al cono de escorias se encuentran lavas basálticas relativamente más fluidas a veces brechosas.

El cráter de Pata de Gallo, corta la espesa secuencia explosiva próxima de Hule, y por lo tanto es posterior a la formación del maar tratándose de un pequeño cono satelital. La edad de su formación se discutirá en apartados subsiguientes.

\section{PETROQUÍMICA}

La base de datos disponible se conforma de cuatro análisis de elementos mayores correspondientes al cono intra-maárico de Hule, sólo uno de ellos con trazas, (McBirney y Williams, 1965; Tournon, 1984; Prosser y Carr, 1987), y un análisis de un pómez juvenil de la tefras de Hule (Soto, 1999). Por otra parte, existe un conjunto de 8 análisis de elementos mayores y traza (Malavassi, 1991), ciertamente de Hule, pero de ubicación desconocida (paredes del maar o del cono piroclástico), denominadas como "sin diferenciar", que se han utilizado para completar una caracterización general y tan solo como comparación.

Cuando se utiliza el diagrama de clasificación álcalis vs. sílice de Le Maitre et al. (1989), las rocas definen una serie con afinidades calcoalcalinas que comprende desde basaltos, andesitas basálticas hasta andesitas (Fig.12) en general con valores de $\mathrm{K}$ intermedios de acuerdo a Gill (1981). Las muestras correspondientes al cono intramaárico son principalmente basálticas $\left(\mathrm{SiO}_{2} 50,54-51,18 \%\right)$ y una de ellas transicional al campo andesita basáltica $\left(\mathrm{SiO}_{2} 52,61 \%\right)$. La muestra del flujo de pumíceos de Hule es, en 


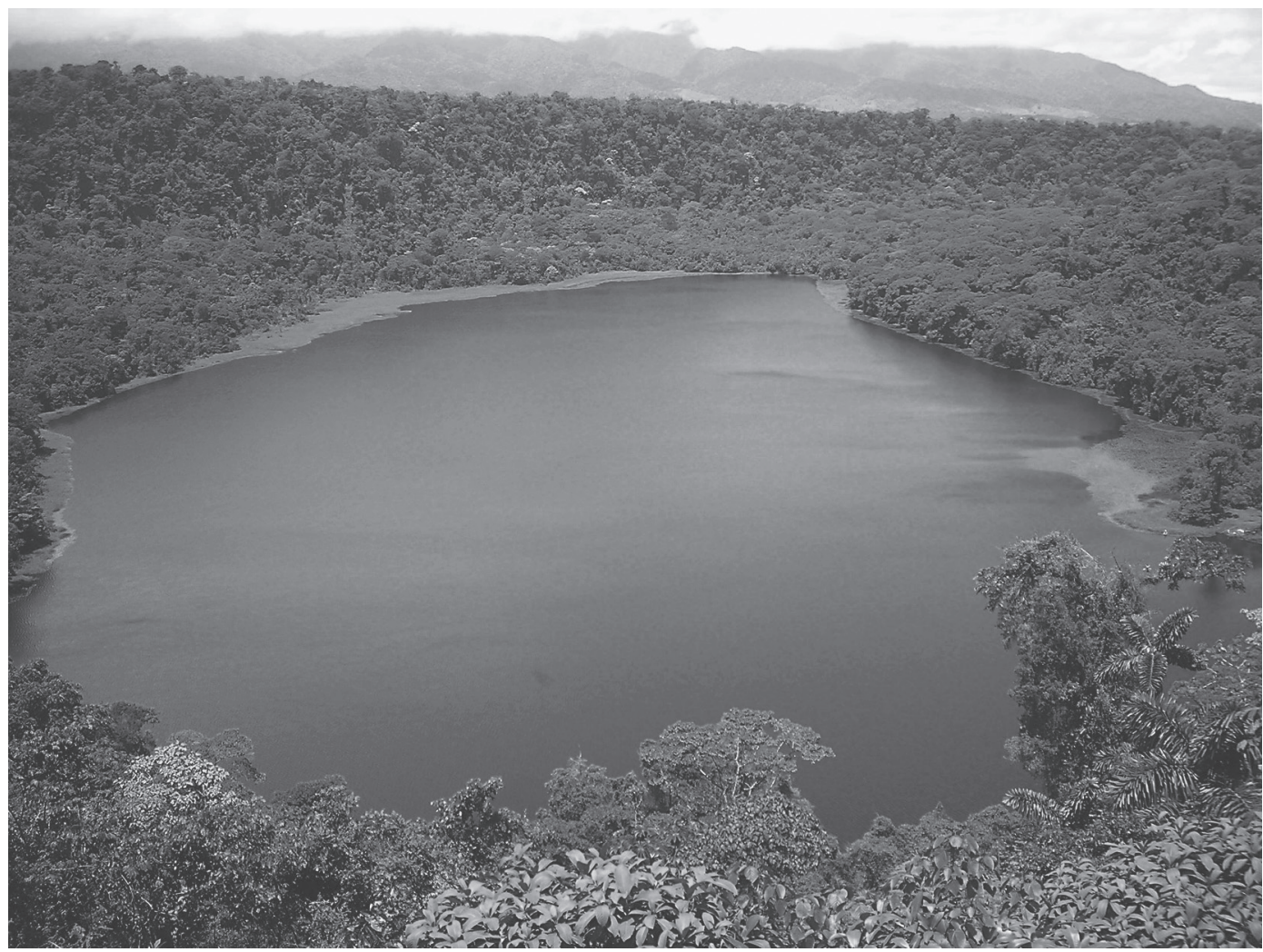

Fig. 11: Vista del cráter y Laguna Hule. En el sector de la derecha el cono intramaárico de Bosque Alegre.

cambio, andesítica (con anfíbol en su moda) y un mayor porcentaje de sílice $\left(\mathrm{SiO}_{2}, 62,29 \%\right)$. Sólo una muestra correspondiente al grupo"sin diferenciar"se aleja de la tendencia basáltica hacia el sector andesítico.

Es evidente una homogeneidad en los valores de sílice, alúmina y calcio para cada grupo (Fig. 13A), mientras que el resto de los óxidos muestra escasas fluctuaciones. Existe alguna dispersión en el flujo piroclástico pumíceo (P09) y las muestras 150,182 y 141 en los valores de elementos como álcalisis (Cuadro 1), que se estima es debido a fenómenos de lixiviación y/o alteración más propicio en rocas piroclásticas.

$\mathrm{La}$ tendencia del $\mathrm{CaO}$ y $\mathrm{MgO}$ al incrementar el $\mathrm{SiO}_{2}$ (Figs.13 B y C) responde al patrón normal de diferenciación en la evolución de una serie de muestras cogenéticas, aunque no puede descartarse la participación de una componente de mezcla. Las concentraciones mayores de $\mathrm{CaO}$ y $\mathrm{MgO}$ se observan en muestras del cono intramaárico donde estos elementos están presentes en las fases mineralógicas olivino y piroxeno. Valores comparables de $\mathrm{MgO}$ se observan en la muestras 69 y 244 del grupo Hule "sin diferenciar". El flujo piroclástico pumíceo (P09) se encuentra en el otro extremo del conjunto con los menores contenidos de estos elementos (ver $\mathrm{CaO}$ en Fig. $13 \mathrm{~A}$ ).

La química de elementos menores disponible se limita a los términos más básicos en sus facies lávica y piroclástica. Cuando se utilizan gráficos compatible-compatible ( $\mathrm{Cr}$ vs. Ni, figura $13 \mathrm{D}$ ), la muestra del cono intramaárico (P02) se ubica dentro de la tendencia con la serie de muestras "sin diferenciar", en el extremo menos evolucionado. Esta tendencia es menos ajustada en los diagramas compatible-incompatibles como RbZr (Fig.13 E), donde se destacan bajos valores de $\mathrm{Rb}$ para $\mathrm{P} 02$. Los contenidos y variaciones de $\mathrm{Sr}$ acompañan al $\mathrm{CaO}$ y la alúmina (Cuadro1) en la 


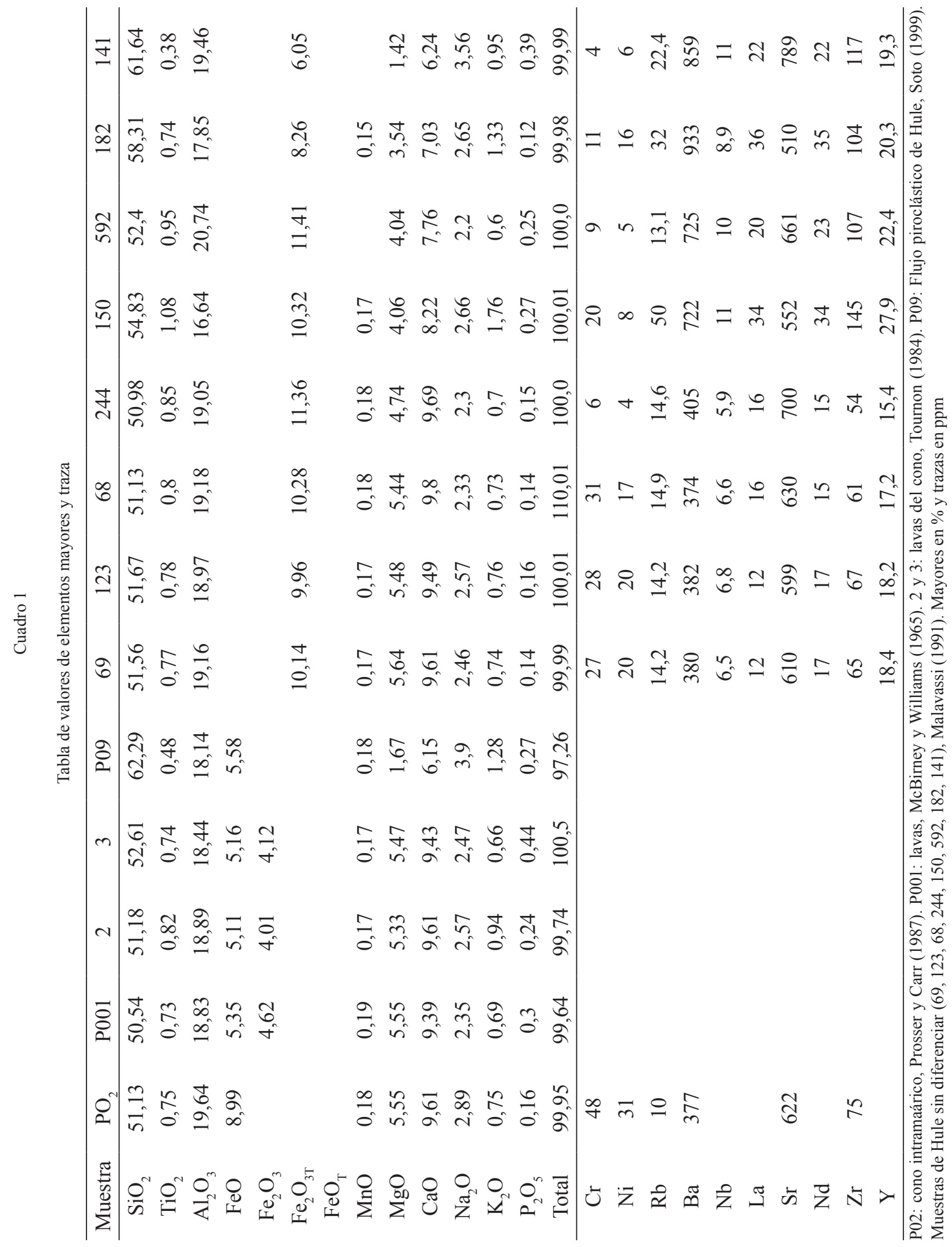




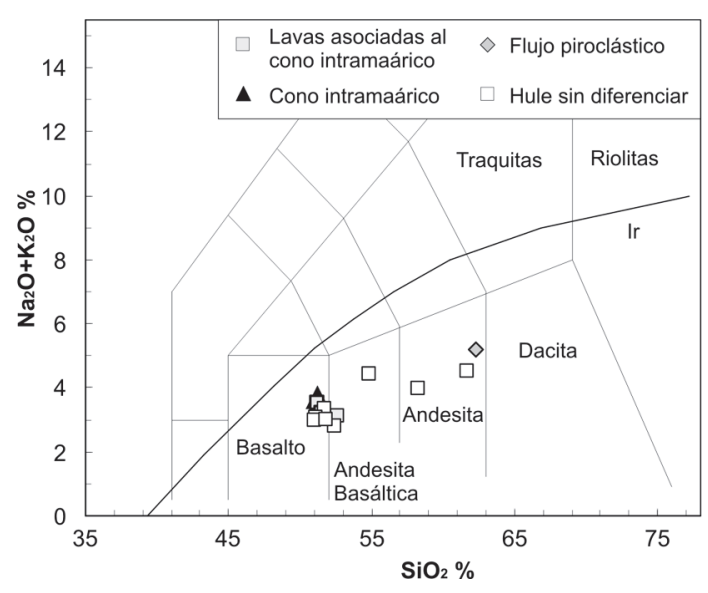

Fig. 12: Clasificación álcalis vs. sílice de Le Maitre et al. (1989). Ir: línea de subdivisión de campos alcalino y subalcalino de Irvine y Baragar (1971).

participación de plagioclasa como componente de estas rocas.

El conjunto de muestras de Hule "sin diferenciar" presenta alta correlación entre si utilizando los diagramas de variación $\mathrm{Nb}-\mathrm{Zr}$, probablemente a traves de cristalización fraccionada (Fig. 13 F).

Alvarado (1984) destacó la composición de los basaltos como de alta alúmina, y utilizando el orden de cristalización de los fenocristales (Mt + Plag, seguido de Ol y finalmente Cpx) estimó una temperatura de cristalización de 1150$1250^{\circ} \mathrm{C}$ y una presión de vapor de agua inferior a $0,7 \mathrm{kbar}$, equivalente a $2,1 \mathrm{~km}$ de profundidad. Por otra parte, de acuerdo a la composición química y la presencia de anfíbol modal en los flujos de pumíceos, éstos podrían ser el producto de un magma andesítico proveniente de una cámara magmática localizada a mayor profundidad (mayor a 2-4,5 km, rango en el que se ha determinado la estabilidad para el anfíbol de fundidos andesíticos a riolíticos, Maksimov, 2008). Es posible pensar que el contacto entre los dos fluidos de distintas composiciones pudo ser el disparador de la erupción, entendiendo que el magma andesítico habría podido intruir a la cámara magmática basáltica a unos $2 \mathrm{~km}$ de profundidad.

Resulta claro, sin embargo, que la información disponible no permite efectuar mayores precisiones sobre la génesis de estas rocas ni sobre su termobarometria. Para ello sería necesario una mayor base de datos de elementos mayores y menores, microsonda electrónica y aún relaciones isotópicas, todo ello fuera del alcance de la presente investigación.

\section{EDAD DE LA ERUPCIÓN}

Varios estudios anteriores han aportado un gran número de dataciones radiocarbón (Melson et al., 1988; Malavassi et al., 1990; Soto, 1999; Horn, 2001, Alvarado \& Salani, 2004; Cuadro 2) consensuando una edad de aproximadamente 2800 a.P. para el evento volcánico de Hule. En efecto, Soto (1999) y Alvarado \& Salani (2004) consideraron que los productos con pómez con anfíbol, provenían del volcán Congo (sensu Melson et al., 1988), mientras que las tobas estratificadas suprayacentes se asociaban a Hule y para ello se tomaba la edad reportada por Malavassi et al. (1990). Sobre estos mismo principios cronológicos, Horn (2001) fijó sus correlaciones e interpretaciones cronológicas de su rica base de datos radiocarbónicos.

No obstante, la edad del maar ha sido recientemente revisada a la luz de las nuevas evidencias vulcanológicas, estratigráficas, edafológicas y arqueológicas.

Por ejemplo, al re-evaluar los mapas de isopacas y isopletas de Alvarado \& Salani (2004), se evidenciaba que los depósitos pumíceos, originalmente atribuidos al Congo, en realidad parecían estar más asociados a Hule, aunque en su momento no fueron claramente visualizados baja esta interpretación.

Por otro lado, la supuesta existencia de dos grandes eventos explosivos (Congo a los 5800, Hule a los 2800 años atrás) con un periodo de inactividad de 3000 años, nos suministraba un lapso suficiente para la formación de un suelo orgánico y edafológicamente bien desarrollado entre ambos eventos explosivos. No obstante, la secuencia eruptiva no presenta en ningún caso un espeso paleosuelo intercalado, tal y como debería de esperarse bajo las condiciones tropicales en un lapso de tres milenios. En efecto, contrario a lo originalmente esperado, la materia orgánica carbonizada 

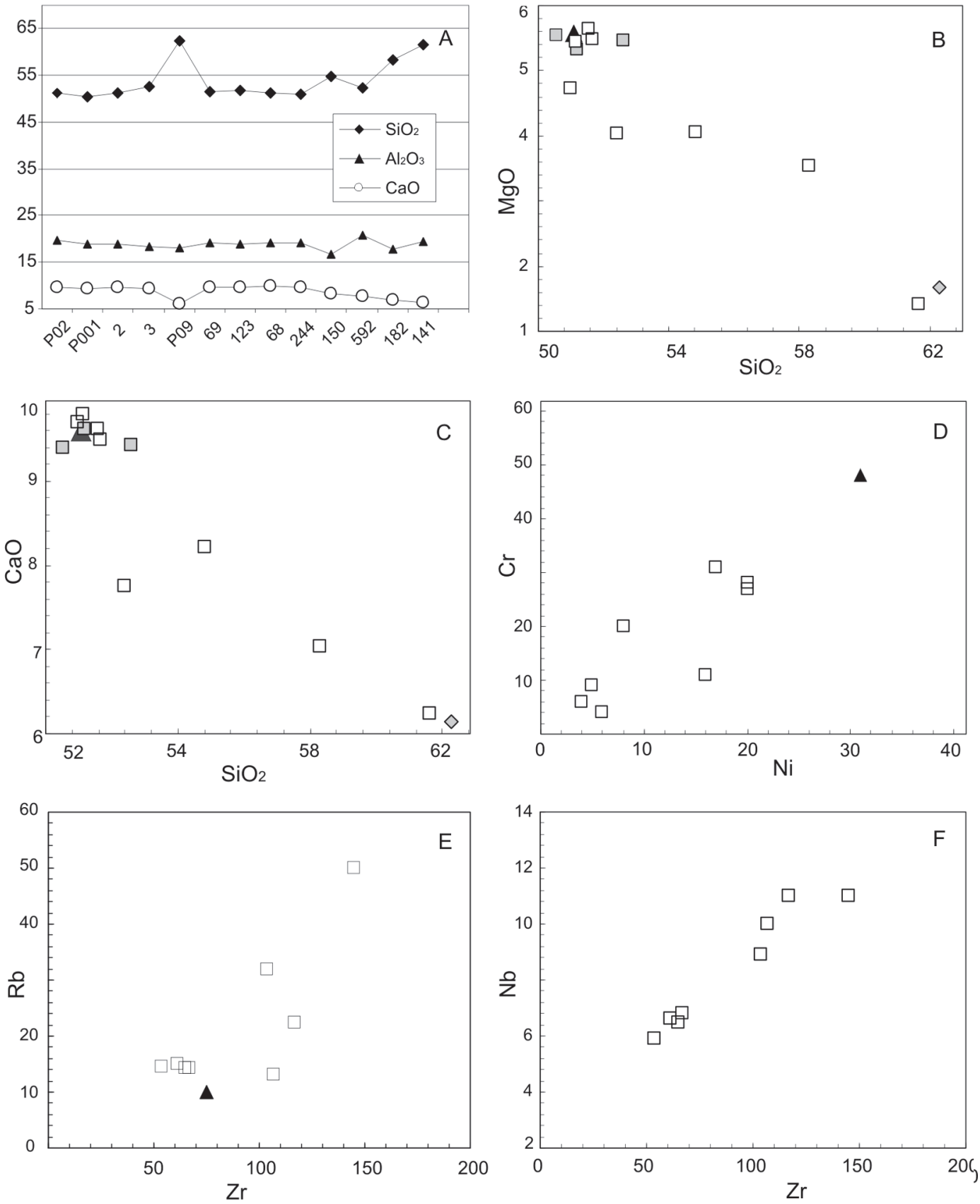

Figura 13: Diagramas de variación de elementos mayores y menores. B, C, D E, F, misma simbología que en la figura 12.

(suelos húmicos, debris orgánicos carbonizado) era abundante en la base de la secuencia correspondiendo al paleobosque carbonizado y al paleosuelo regional. Así, los eventos explosivos constituyen una secuencia contínua desde la base al techo sin interrupciones temporales importantes.

Por ello, las edades reportadas ya sea de la base de los depósitos $(5390 \pm 45$ años a.P., 
Cuadro 2

Dataciones de radiocarbono asociadas con los eventos explosivo de Hule y post-Hule según diversos autores y re-interpretadas en el presente trabajo. Todas las edades son a.P. A (Bronk \& Ramsey, 1995, 2001) B (Stuiver y Reimer, 1993; Hughen et al., 2004)

\begin{tabular}{|c|c|c|c|c|c|c|}
\hline $\begin{array}{l}\text { Referencia o Núme- } \\
\text { ro Laboratorio }\end{array}$ & Muestras y contexto & Edad & $\begin{array}{l}\text { Rango edad } \\
\text { calibrada (2 } \\
\text { s), al nivel } \\
\text { de máxima } \\
\text { confiden- } \\
\text { cia A }\end{array}$ & $\begin{array}{l}\text { Edad prome- } \\
\text { dio calibrada }\end{array}$ & $\begin{array}{c}\text { Rango edad } \\
\text { calibrada (2 } \\
\text { s), al nivel } \\
\text { de máxima } \\
\text { confiden- } \\
\text { cia B }\end{array}$ & $\begin{array}{l}\text { Edad prome- } \\
\text { dio calibrada }\end{array}$ \\
\hline Horn (2001) & $\begin{array}{l}\text { Sedimentos base núcleo } 1 \text {, } \\
\text { laguna Hule }\end{array}$ & $7580 \pm 90$ & $8190-8550$ & 8370 & $8193-8545$ & 8369 \\
\hline Horn (2001) & $\begin{array}{c}\text { Sedimentos base núcleo 3, } \\
\text { laguna Hule }\end{array}$ & $6910 \pm 90$ & $7590-7940$ & 7765 & $7594-7879$ & 7737 \\
\hline $\begin{array}{l}\text { Hurtado de Mendoza } \\
\qquad \begin{array}{c}\text { (2006) } \\
\text { A-13649 }\end{array}\end{array}$ & $\begin{array}{c}\text { Madera carbonizada T.O } \\
\text { Cariblanco. Base secuencia } \\
\text { Holocena }\end{array}$ & $5390 \pm 45$ & $6170-6290$ & 6230 & $6172-6289$ & 6230 \\
\hline Soto (1999) & $\begin{array}{c}\text { Tronco en flujo piroclástico, } \\
\text { quebrada Berros }\end{array}$ & $\begin{array}{c}5330 \pm \\
130\end{array}$ & $5750-6400$ & 6075 & $5886-6355$ & 6120 \\
\hline Melson et al. (1988) & $\begin{array}{l}\text { Tronco-flujo piroclástico } \\
\text { quebrada Higuera }\end{array}$ & $\begin{array}{c}5140 \pm \\
110\end{array}$ & $5650-6200$ & 5925 & $5653-6182$ & 5917 \\
\hline $\begin{array}{l}\text { Alvarado \& Salani } \\
\text { (2004) }\end{array}$ & $\begin{array}{l}\text { Lahar con troncos quema- } \\
\text { dos Río Tercero }\end{array}$ & $5110 \pm 80$ & $5650-6200$ & 5925 & $5651-6004$ & 5827 \\
\hline $\begin{array}{c}\text { Horn }(2001) \\
\beta-30430\end{array}$ & - & $3230 \pm 80$ & $3320-3650$ & 3485 & $3321-3641$ & 3481 \\
\hline $\begin{array}{c}\text { Horn }(2001) \\
\beta-56233\end{array}$ & $\begin{array}{l}\text { Madera a 2,66 m en el } \\
\text { núcleo } 3 \text { de Hule }\end{array}$ & $3080 \pm 70$ & $3450-3070$ & 3260 & $3136-3445$ & 3290 \\
\hline $\begin{array}{l}\text { Malavassi et al. } \\
\qquad(1990)\end{array}$ & $\begin{array}{l}\text { En tefras en el borde del } \\
\text { cráter Pata de Gallo }\end{array}$ & $2730 \pm 50$ & $2750-2950$ & 2850 & $2753-2929$ & 2841 \\
\hline $\begin{array}{c}\text { Horn }(2001) \\
\text { ß-73925 }\end{array}$ & $\begin{array}{c}\text { Hoja a } 1,45 \mathrm{~m} \text { en Hule } \\
\text { Core } 3\end{array}$ & $1250 \pm 60$ & $1050-1300$ & 1175 & $1056-1293$ & 1174 \\
\hline $\begin{array}{c}\text { Horn }(2001) \\
\text { ß-73926 }\end{array}$ & $\begin{array}{c}\text { Hoja a 2,94 m en Hule } \\
\text { Core } 3\end{array}$ & $2230 \pm 60$ & $2100-2350$ & 2230 & $2112-2350$ & 2231 \\
\hline $\begin{array}{l}\text { Horn }(2001) \\
\text { OS-4412 }\end{array}$ & $\begin{array}{l}\text { Hoja sobre ceniza Núcleo } \\
\text { 1-María Aguilar }\end{array}$ & $2520 \pm 30$ & $2650-2480$ & 2560 & $2488-2644$ & 2566 \\
\hline $\begin{array}{c}\text { Horn }(2001) \\
\text { ß-56234 }\end{array}$ & $\begin{array}{l}\text { Fragmento de madera Nú- } \\
\text { cleo } 3 \text { María Aguilar }\end{array}$ & $2610 \pm 70$ & $2870-2460$ & 2665 & $2470-2864$ & 2667 \\
\hline
\end{tabular}

Hurtado de Mendoza, 2006), o de la parte media a través de tronquitos quemados dentro de los flujos piroclásticos (5140 \pm 110 años y $5330 \pm 130$ años a.P.; Melson et al., 1988; Soto, 1999) resultaron muy similares a la de los grandes troncos parcialmente quemados incorporados en el lahar de Río Tercero (5110 \pm 45 años a.P.; Alvarado \& Salani, 2004).

Por otro lado, sobre el suelo que cubre las tefras de Hule se hallaron restos arqueológicos pertenecientes al período precolombino Arcaico (7000-
4000 a.P.), del Formativo Medio y de Integración Cacical (4000-1800 a.P.), en donde Hurtado de Mendoza, (2006) presenta dos fechas ${ }^{14} \mathrm{C}$ del sitio Los Higuerones (Tanque de Oscilación), de tiempos cerámicos 2610 \pm 60 a.P. (Beta 196735 no calibrada, lapso $1 \sigma=720-600$ a.C.) $2525 \pm 50$ a.P. (Arizona 13648 no calibrada, lapso $1 \sigma=625-525$ a.C.) que marcan la transición entre los dos períodos arqueológicos. Esto plantearía una incongruencia temporal con la edad previamente asignada a Hule, que sumada a las evidencias anteriores, lleva a la conclusión 


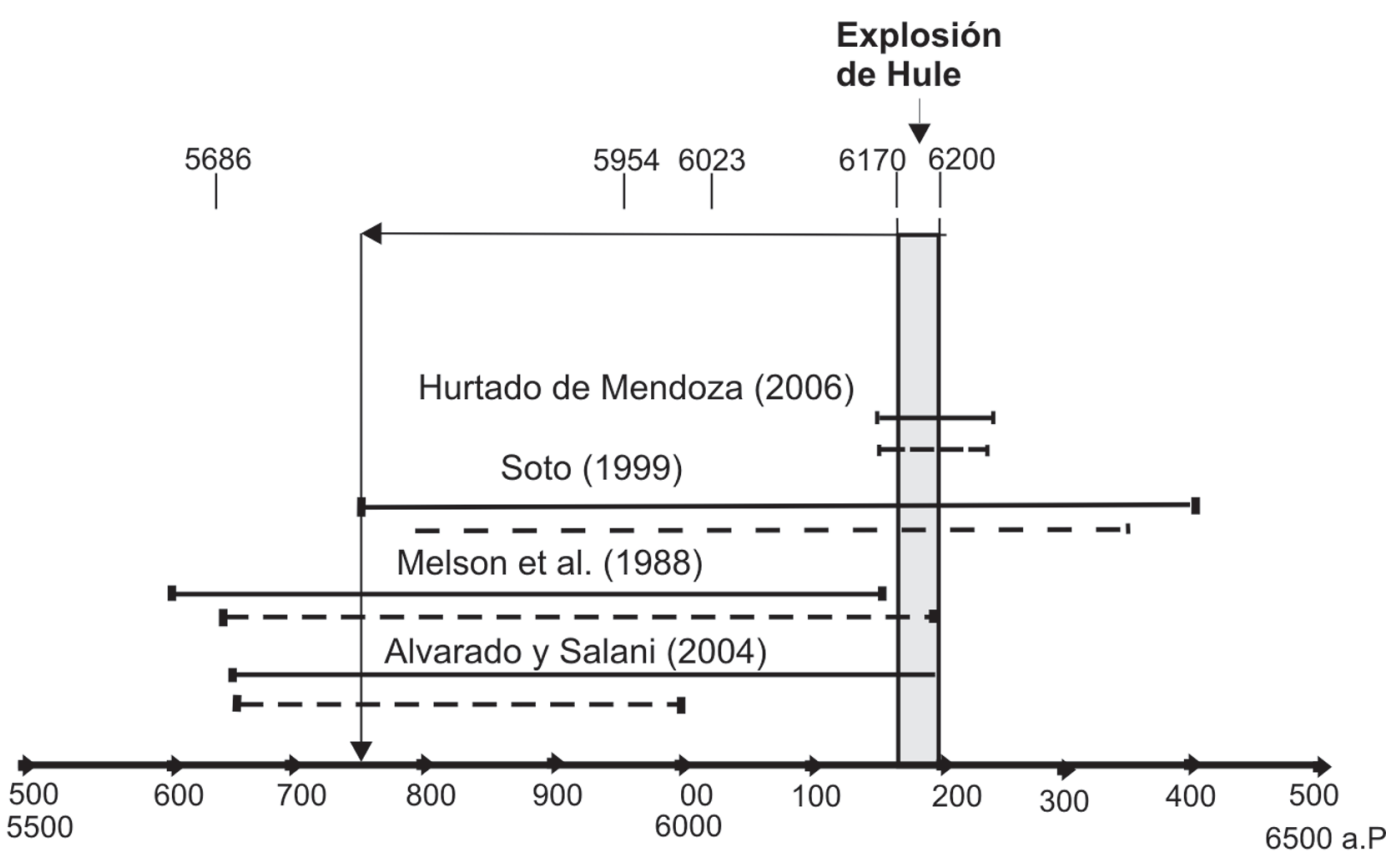

• Bronk Ramsey $(1995,2001)$

ローーーー・ Stuiver y Reiner(1993) Hughen et al.(2004)

Rango de edades calibradas

Fig. 14: Rangos de variaciones de las edades ${ }^{14} \mathrm{C}$ calibradas de Hule.

que las tefras deberían ser más antiguas que los 2800 años referidos originalmente.

De igual modo, si analizamos los rasgos morfológicos del volcán Congo, no muestran un cráter cuspidal por donde debieron de haber descendido los presuntos flujos piroclásticos relacionados al centro eruptivo. Más bien, la morfología da a entender que se trata de un volcán dormido por varios miles de años. En efecto, Malavassi et al. (1990) dataron un depósito en unos 30000 años a.P. Adicionalmente, profundos cañones que nacen de la depresión de la laguna Hule sugieren una edad más antigua de formación que los 2800 años previamente propuestos.

Así es que, la compilación de la serie de datos publicados, nos suministra más bien edades más antiguas y cronológicamente similares. Según los métodos de calibración de Bronk Ramsey (1995, 2001), de Stuiver y Reimer (1993) y de Hughen et al. (2004), la edad promedio de Hule estaría entre 6038 y 6023 a.P. (promedio de fechas promedios ya calibradas) o entre 5964 y 5686 a.P. (promedio máximos y mínimos de las fechas calibradas). Si se tienen en cuenta en cambio los rangos de las edades calibradas, resulta un gráfico en el que la superposición es notoria y se observa que todas ellas se traslapan en el estrecho lapso de 6170 a 6200 años a.P., con una edad media de 6185 a.P. (Figura 14). Estos valores estarían enmarcando el rango de la gran explosión freatomagmática de Hule definiendo una edad de por lo menos 6200 años a.P. Las muestras que aportan la edad de $6,2 \mathrm{ka}$ (cuatro en total), fueron recolectadas por autores diferentes, en años diferentes, analizadas en laboratorios separados y bajo contextos geológicos separados varios kilómetros entre sí y en diferentes tipos de depósitos (flujos piroclásticos, lahares asociados y la base de la secuencia explosiva inicial). Todo ello nos da un mayor grado de confiabilidad.

Pero, entonces, qué pasa con las edades reportadas por Horn (2001) y calibradas entre 8,3 y 7,7 ka para sedimentos orgánicos recolectados de la laguna Hule (ver Cuadro 2), que serían entre 
1,6 y 2,2 ka más antiguas que la edad asumida de 6,2 ka? Acá recurrimos a los mismos criterios de Horn (2001), en donde considera que pueden o deben de estar contaminadas con carbono antiguo (old carbon), debido a que quizás la laguna como tal puede ser un conducto preferencial de salida de gases $\left(\mathrm{CO}, \mathrm{CO}_{2}\right)$, particularmente por el hecho de que existen fenómenos recurrentes de mortandad de peces y cambios de color de las aguas, de un azulado a rojizo, además de que se sabe de la presencia de salideros de gases de diversa índole (Alvarado et al., 2007; Tassi et al., 2009).

De toda la información expuesta se desprende entonces que la enorme explosión que dio origen a la laguna Hule debió de originarse con toda seguridad al menos hace unos 6200 años y que el volcán Congo previo al inicio de la actividad de Hule, estuvo dormido por 22000 - 24000 años, permitiendo la formación de suelos bien desarrollados y de un denso bosque tropical lluvioso, similar al presente. Se puede interpretar también que toda la secuencia de tefras (flujos, oleadas y caídas, aunado a los balísticos) pertenece a una única serie de fases eruptivas asociadas con el vulcanismo de Hule. La información arqueológica aportada por Hurtado de Mendoza (2006) apoya este rango temporal.

Por otra parte, no se observaron depósitos claramente asociables con la fase explosiva de menor tamaño que originó el cráter maárico de Pata de Gallo. En efecto, dicho cráter se instaló posteriormente a la formación del maar de Hule dado que corta toda la secuencia explosiva anteriormente expuesta. En los cortes del borde cratérico de Pata de Gallo, la estratigrafía no revela con claridad los depósitos asociados, dado que quizás se generó un efecto de sombrilla, con una zona de sombra de no depositación en los afloramientos accesibles. Tampoco se encontraron restos orgánicos para ser datados de nuevo. Pese a ello, pensamos que la edad de 2800 años a.P. reportada por Malavassi et al. (1990), y originalmente asociada a la edad de formación de Hule, más bien debe de corresponder con la edad de formación del cráter de explosión o maar de Pata de Gallo. Lo anterior está justificado en el hecho de que el lugar en donde se tomó la muestra para datar, fue justo en el borde sureste de dicho cráter (E. Malavassi, com. verbal, 2009).

Finalmente, las cenizas de 1700 y 670 años a.P., datados por Horn (2001), podrían provenir del Poás más que de Hule. Dado que se carecen de descripciones sobre el tipo de material (granulometría, composición mineralógica y química) que se perforó y recuperó de las lagunas Hule y María Aguilar, no se puede concluir más al respecto sobre el posible foco eruptivo.

\section{DISCUSIÓN Y CONCLUSIONES}

El estudio detallado de unas 60 secciones estratigráficas junto con la revisión de las dataciones radiométricas, aspectos pedogenéticos aunado a evidencias geoarqueológicas, nos permiten establecer que la edad al día de hoy más congruente con la formación de la laguna Hule sería de 6200 años y no la de 2800 años antes del presente, correspondiendo esta última edad al parecer con la formación del maar satelital de Pata de Gallo. Así, la secuencia explosiva previamente asociada al volcán Congo (originalmente referida a 5800 años a.P.) y la de Hule, están relacionadas $\mathrm{y}$ corresponden a un mismo evento.

Una nueva secuencia estratigráfica simplificada se puede reconstruir referente a las diferentes facies explosivas de Hule sustentada en las consideraciones estratigráficas, morfológicas, composicionales y cronológicas expuestas. El conjunto de datos lleva a la reinterpretación de la historia eruptiva de Hule que iniciaría cuando un magma andesítico, en ascenso a lo largo de una zona de debilidad cortical se encuentra con el nivel o los niveles freáticos regionales, ubicados a unos 200$300 \mathrm{~m}$ (aprox. 500-600 m s.n.m.) bajo el nivel de terreno circundante (800 m s.n.m.). El magma rico en volátiles interactúa con las aguas freáticas y produce una vaporización y sobrepresión simultánea que desencadena una serie de erupciones freatomagmáticas.

La primera fase correspondería a la apertura de la gran depresión volcánica con la concomitante formación de enjambres de oleadas de pómez (blast) y flujos piroclásticos, así como bre- 
chas freatomagmáticas de caída (niveles SFB-1 y TE-1). Este evento arrasó el bosque primario existente, dejando en lugar una masa de detritos orgánicos parcialmente carbonizados (nivel DOB), cubiertos por varios metros de fragmentos explosivos. A continuación, una fase volumétrica menor, pero de importancia regional para la correlación de las unidades, se manifiesta como una oleada húmeda de cenizas violáceas a rojizas (capa CV). Nuevos pulsos de flujos piroclásticos y oleadas acompañantes, sumados a la caída balística siempre presente, generaron nuevos depósitos explosivos (nivel SFB-2), que culminaron con las más extendidas nubes de cenizas rasantes (oleadas piroclásticas de la TE-3), que incluso sobrepasaron el cañón del río Toro al oriente, en parte favorecidas por la dirección de los vientos. Un período de calma aparente (horas?, días?), fue suficiente para que los ríos provenientes del volcán Congo y otros tributarios, permitieran reestablecer su sistema de drenaje sobre el paisaje desolado de varios metros de espesor producto de los nuevos depósitos piroclásticos.

En un evento posterior y relativamente mucho más tranquilo, un nuevo magma desgasificado y más máfico (basáltico andesítico hasta basáltico), dio origen a una fase eruptiva estromboliana con coladas de lava subordinadas dentro de la depresión de Hule, construyendo el cono de escorias de Bosque Alegre. La impermeabilización del piso de la laguna por la alteración de los productos eruptivos debido a los gases fumarólicos, debió de originar arcillas y con ello, las condiciones ideales para la formación de la laguna Hule y las otras dos más pequeñas.

El carácter poligenético de Hule se refleja en una eruptividad recurrente que responde a distintos estilos y composiciones. Las fases eruptivas principales $(6,2 \mathrm{ka})$ son de origen freatomagmáticas con composiciones intermedias. A ello le siguió la fase más básica que se inicia con un vulcanismo estromboliano construyendo al menos un cono piroclástico intramaárico y finaliza con disminución rápida de volátiles y emisión de episodios lávicos más fluidales.

Resulta conocido que la actividad maárica suele no extenderse por mucho tiempo con base en los pocos casos históricos y que aproximada- mente un $95 \%$ de los conos de escorias se forman en menos de un año y un alto porcentaje en un mes (ver Wood, 1980). Sin embargo, los registros geológicos indican que algunos maares así como conos de escoria suelen tener una historia algo más compleja y prolongada (Schmincke, 2004). Al parecer este fue nuestro caso, en donde una nueva fase explosiva $(2.8 \mathrm{ka})$ responsable de la formación de un segundo episodio maárico satelital origina el cráter de Pata de Gallo. Una secuencia similar, con formación de dos etapas de maar atribuida a una fase vulcaniana, y posteriormente la evolución a estromboliana, presenta el volcán Galunggung en Indonesia (Gourgaud et al., 2000). Más recientemente, Moreno \& Lara (2009) estudian en Chile el maar poligenético Riñinahue y Carrán, el primero en el mismo lugar de un maar preexistente y el segundo en el sector del antiguo maar Laguna Negra. En estos casos también la erupción finalizó con la instalación de un cono estromboliano.

\section{AGRADECIMIENTOS}

Al Instituto Costarricense de Electricidad que permitió la concreción de la presente investigación a través de la financiación de los sucesivos trabajos de campo. Al Sr. Francisco Arias. Al Dr. Luis Hurtado de Mendoza y a Gerardo Soto por las fructíferas discusiones y al revisor del manuscrito por sus oportunas sugerencias que han contribuido a enriquecer este trabajo.

\section{REFERENCIAS}

ALVARADO, G.E., 1984: Aspectos petrológicosgeológicos de los volcanes y unidades lávicas del Cenozoico Superior de Costa Rica.- vii +183 págs. Univ. de Costa Rica, San José [Tesis Lic.].

ALVARADO, G.E. \& SALANI, F.M., 2004: Tefroestratigrafía (40 000-2000 a.P.) en el sector Caribe de los volcanes Barva, Congo y Hule, Cordillera Central, Costa Rica.Rev. Geol. Amér. Central, 30: 59-72. 
ALVARADO, G.E., SOTO, G.J., SCHMINCKE, H.U., BOLGE, L.L. \& SUMITA, M., 2006: The 1968 andesitic lateral blast eruption at Arenal volcano, Costa Rica.- J. Volcanol. Geotherm. Res. 157: 9-33.

ALVARADO, G.E., SOTO, G.J., PULLINGER, C.R., ESCOBAR, R., BONIS, S., ESCOBAR, D. \& NAVARRO, M., 2007: Volcanic activity, hazards, and monitoring.- En: J. BUNDSCHUCH \& G.E. ALVARADO (eds): Central America: Geology, Resources and Hazards.- Taylor \& Francis, Londres, 2: 1155-1188.

BRONK RAMSAY, C., 1995: Radiocarbon calibration and analysis of stratigraphy: The $\mathrm{OxCal}$ program.- Radiocarbon, 37(2): 425-430.

BRONK RAMSAY, C., 2001: Development of the radiocarbon calibration program OxCal.Radiocarbon, 43 2A): 355-363.

CARR, M. J., I. SAGINOR, G. E. ALVARADO, L. L. BOLGE, F. N. LINDSAY, K. MILIDAKIS, B. D. TURRIN, M. D. FEIGENSON \& C. C. SWISHER, III., 2007: Element fluxes from the volcanic front of Nicaragua and Costa Rica.Geochem. Geophys. Geosyst. 8, Q06001. DOI: 10.1029/2006GC001396.

CAS, R., A.F. \& WRIGHT, J.V., 1987: Volcanic successions. Modern and ancient.- 528 págs. Unwin Hyman, London.

GILL, J.B., 1981: Orogenic Andesites and Plate Tectonics.- 385págs. Springer-Verlag.

GOCKE, K., BUSSING, W. \& CORTÉS, J., 1987: Morphometric and basic limnological properities of the Laguna de Río Cuarto, Costa Rica.- Rev. Biol. Trop. 35(2): 277-285.

GOCKE, K., 1996-1997: Basic morphometric and limnological properties of Laguna Hule, a caldera lake in Costa Rica.- Rev. Biol. Trop. 44/45: 537-548.
GOURGAUD, A., THOURET, J.C. \& BOURDIER, J.L., 2000: Stratigraphy and textural characteristics of the $1982 \pm 83$ tephra of Galunggung volcano (Indonesia): implications for volcanic hazards.- J. Volcanol. Geotherm. Res. 104: 169-186.

HABERYAN, K.A. \& HORN, S.P., 1999: Chemical and physical characteristics of seven volcanic lakes in Costa Rica.Brenesia, 51: 85-95.

HORN, S.P., 2001: The age of the laguna Hule explosion crater, Costa Rica, and the timing of subsequent tephra eruptions: evidence from lake sediments.- Rev. Geol. Amér. Central, 24: 57-66.

HORN, S.P, 2006: Late Quaternary lake and swamp sediments: Recorders of climate and environment.- En: J. BUNDSCHUH \& G.E. ALVARADO (eds): Central America: Geology, Resources and Hazards. Balkema: 423-441.

HUGHEN, K.A., BAILLIE, M.G.L., BARD, E., BAYLISS, A., BECK, J.W., BERTRAND, C.J.H., BLACKWELL, P.G., BUCK, C.E., BURR, G.S., CUTLER, K.B., DAMON, P.E., EDWARDS, R.L., FAIRBANKS, R.G., FRIEDRICH, M., GUILDERSON, T.P., KROMER, B., MCCORMAC, F.G., MANNING, S.W., BRONK RAMSEY, C., REIMER, P.J., REIMER, R.W., REMMELE, S., SOUTHON, J.R., STUIVER, J.R., TALAMO, S., TAYLOR, F.W., VAN DER PLICHT, J., \& WEYHENMEYER, C.E., 2004: Marine04 Marine radiocarbon age calibration, 26-0 ka B.P.- Radiocarbon, 46: 1059-1086.

HURTADO DE MENDOZA, L., 2006: Investigaciones arqueológicas en el Proyecto Hidroeléctrico Cariblanco, Sarapiquí de Alajuela.- 12 págs. Informe Final, presentado a la Comisión Arqueológica Nacional, Mayo 2006. Área de Gestión Ambiental, P.H. Cariblanco, ICE, Colonia del Toro, Alajuela. 
IRVINE, T.N. \& BARAGAR,W.R.A., 1971: A guide to the chemical classification of the common volcanic rocks.- Can. J. Earth. Sci. 8 :523-548.

LE MAITRE, R.W, BATEMAN, P., DUDEK, A., KELLER. J., LAMEYRE, J., LE BAS, M.J., SABINE, P.A., SCHMID, R., SORENSEN, H., STREKEISEN A., WOOLLEY, A.R, ZANETTIN, B., 1989: A classification of igneous rocks and glossary of terms.- 256 págs. Blackwell, Oxford.

MAKSIMOV,A. P. 2008: A Physicochemical Model for Deep Degassing of Water-Rich Magma.J. Volcanol. Seismology. 2(5): 356-363.

MALAVASSI, E., 1991: Magma sources and crustal processes at the terminous of the Central American Volcanic Front.- 435 págs. Univ. de Santa Cruz, California [Tesis Ph.D.].

MCBIRNEY, A.R. \& WILLIAMS, H., 1965: Volcanic history of Nicaragua.- Univ. Calif. Publ. Geol. Sci. 55: 1-65.

MELSON, W. G., SÁENZ, R., BARQUERO, J. \& FERNÁNDEZ, E., 1988: Edad relativa de las erupciones del Cerro Congo y Laguna Hule.Bol. de Vulcanología OVSICORI, 19: 8-10.

MORENO, H. \& LARA, L., 2009: The polygenetic Carrán and Riñinahue Maar eruptions in the 20th Century: historic cases of reactivations in young Arc Volcanism, Southern Andes $\left(40.2^{\circ} \mathrm{S}\right)$, Chile.- IAVCEI-CVS-IAS. 3IMC Conference. Malargüe, Mendoza. Argentina.

PROSSER, J. \& CARR, M.J., 1987: Poás volcano, Costa Rica: Geology of the summit region and spatial and temporal variations among the most recent lavas.- J. Volcanol. Geotherm. Res. 33: 131-146.

SCHMINCKE, H.U., 2004: Volcanism.- 324 págs. Springer, Berlín.

SOTO G.J., 1999: Geología Regional de la hoja Poás (1:50 000).- En: ALVARADO, G.E. y MADRIGAL, L.A. (eds): Estudio Geológico-Geotécnico de Avance a la Factibilidad del P.H. Laguna Hule. ICE, San José [Inf. Interno]: 15-45.

STUIVER, M. \& REIMER, P.J., 1993: Extended ${ }^{14} \mathrm{C}$ database and revised CALIB radiocarbon calibration program.- Radiocarbon, 35: 215-230.

TASSI, F., VASELLI, O., FERNANDEZ, E., DUARTE, E., MARTINEZ, M., DELGADO HUERTAS, A. \& BERGAMSCHI, F., 2009: Morphological and geochemical features of crater lakes in Costa Rica: an overview.- J. Limnol., 68(2): 193-205.

TOURNON, J., 1984: Magmatismes du Mesozoique a l'actuel en Amérique Centrale:l'exemple de Costa Rica, des ophiolites aux andésites.- 335 págs. Mém. Sc. Terre Univ. Curie, París: 84-49.

UMAÑA, G., 1993: The planktonic community of Laguna Hule, Costa Rica.- Rev. Biol. Trop. 41(3): 499-507.

WOOD, C.A., 1980: Morphometric evolution of scoria cones.- J. Volcanol. Geotherm. Res. 7: 387-413. 